NBER TECHNICAL PAPER SERIES

\title{
LOW COST STUDENT LABOR: THE USE AND EFFECTS \\ OF THE SUBMINIMUM WAGE PROVISIONS \\ FOR FULL-TIME STUDENTS
}

\author{
Richard B. Freeman \\ Wayne Gray \\ Casey Ichniowski \\ Working Paper No. 765
}
NATIONAL BUREAU OF ECONOMIC RESEARCH
1050 Massachusetts Avenue
Cambridge MA 02138

September 1981

\footnotetext{
The authors would like to thank Sherwin Rosen for his valuable comments on this paper. We have benefitted from the research assistance of Mark Hindal and Wendy Sonnabend. Manuscript typed by Carolyn J. Walker. The research reported here is part of the NBER's research program in Labor Studies. Any opinions expressed are those of the authors and not those of the National Bureau of Economic Research.
} 
Low Cost Student Labor:

The Use and Effects of the Subminimum Wage Provisions

for Full-time Students

\section{ABSTRACT}

Section 14(b) of the Fair Labor Standards Act permits certain classes of employers to pay full-time students a wage fifteen percent below the minimum wage. This study develops a new data base from administrative records, our own survey of participating company and establishment managers, and published information on local labor markets to investigate employer responses to a subminimum wage program.

Our analysis of the full-time student certification program has yielded four general conclusions. First, while the most important users of the program are institutions of higher education, certain non-educational employers in the retail and service sectors employ a sufficiently large and increasing number of students below the minimum wage to suggest that the program has considerable attractiveness in the private sector. Second, area labor market conditions are a major determinant of which establishments with permits to pay students subminimum wages in fact make use of the program and the extent of that use. Establishments in areas characterized by high wages and low levels of unemployment, implying high costs in employing or locating substitute labor, make more use of student subminimum workers than establishments in areas with lower costs for substitute labor. The magnitude of the effect of area wage is, however, sensitive to the precise specification of the full-time student employment equation and the variable used to measure area wage. Although this sensitivity leads to variations in the estimation of the elasticity of substitution between student and other labor, reasonable estimates of this elasticity range from .5 to 1.0. Among company characteristics, unionism reduces program usage, while certain company incentives promote use of the program. Finally, restrictions in the law placed on hours worked at the subminimum appear to be a major reason for failure to employ students under this program.

Richard B. Freeman

Wayne Gray

Casey Ichniowski

National Bureau of Economic Research 1050 Massachusetts Avenue Cambridge, MA 02138

(617) $868-3915$ 


\section{Introduction}

What happens when a subminimum wage is permitted for certain groups of workers in an economy covered by minimum wage?

This question has recently achieved prominence in the United States as a result of suggestions that a youth subminimum provision to be added to the Fair Labor Standards Act. Despite widespread public discussion of the youth subminimum and an enormous literature on the minimum wage, relatively little attention has been given to the existence of a subminimum for one group of youth workers (students) in the current $1 \%$

law. Under Section $14(\mathrm{~b})$ of the Fair Labor Standards Act certain classes of employers subject to the minimum wage provisions of the Act are eligible to pay full-time students less than the minimum wage otherwise applicable in their establishments. For many years, the law was such that relatively few establishments made use of the student subminimum provision. Changes in the law in 1966, and further changes in 1974 and 1977, however, have led to an enormous increase in the use of the student subminimum.

What can be learned from the experience with the student subminimum about employer response to reduced wages for special groups of workers? What factors have led some employers to make more extensive use of the student subminimum than do other employers? What implications can be drawn for a general youth subminimum?

This study develops a new data base for analysis of the student subminimum and uses this data to attempt to answer the preceding questions. As a useable data set relating to the subminimum did not exist when we began our work, considerable effort went into data development. We added to existing administrative records the results of our own telephone survey of firms and published information on local labor markets, so as to have information on the economically interesting variables. The strategy of developing data beyond that on administrative records for the purpose of 
program analysis was necessary due to the lack of important economic variables in administrative records. Our success in data development suggests that this strategy may be useful in analysis of other programs as well.

Our analysis has yielded four general conclusions regarding experience with the student subminimum to the minimum wage.

1) While the most important users of the program are institutions of higher education, private non-educational employers, notably department stores, variety stores, and to a lesser extent food and apparel stores and theatre chains employ a sufficiently large and increasing number of students below the minimum to suggest that the program has considerable attractiveness in the private sector. As the student minimum provisions have become increasingly lenient in recent years, the number of establishments obtaining permits to pay students below minimum wages rose from 2,756 in 1962-1966 to 5,063 in 1967-1974 to 25,985 in 1975-1979. Exclusive of institutions of higher education (not permitted to use the law until 1974) the number of hours covered by the student subminimum increased from $12,067,000$ to $76,102,000$ between 1974 and 1979. Among non-educational users, a substantial proportion of employee hours (10.5\% in 1979) are worked by students at below minimum wages. Even with the sizeable expansion and extensive use of students in college and universities, however, no more than $3-4 \%$ of employed students were employed at the subminimum wage in 1979. Thus the program appears to be an important economic factor for those employers using it but to have only a modest impact on the overall student market.

2) Area labor market conditions are a major determinant of which establishments with permits to pay students subminimum wages in fact make use of the program and the extent of that use. Establishments in areas 
characterized by high wages and therefore high costs of substitute labor make more use of student subminimum workers than establishments in areas with low local wage levels. The magnitude of this effect is, however, sensitive to the precise specification of the FTS employment equation and the variable used to measure "area wage", giving a wide range of estimated elasticities. Consistent with the direction of this result, areas with low levels of unemployment, indicating relatively higher costs in locating and attracting alternative workers, make more extensive use of the program. On the supply side, employment of students at the subminimum is diminished significantly by high alternative wages for young workers.

3) The characteristics of companies also affects program usage, with the presence of unions significantly reducing FTS employment. Company incentives to promote use of the program appear to have a positive effect on usage while less direct reward systems linked to payroll costs or to profit sharing schemes do not increase program use. Part of the ineffectiveness of such programs is the result of establishments in companies with such policies being unaware of their existence.

4) A major reason for failure to employ FTSs relates to the restrictions placed on hours worked at the subminimum, both for the establishment as a whole and for the individual students. Of the 225 establishments we interviewed by mail, $29 \%$ cited these hour restrictions as the most important reason for limited program use.

The remainder of this paper describes the data and analysis on which these conclusions are based. Section II provides a description of the student subminimum provisions in the minimum wage law and of the size of the program under study. Section III develops the research design and model that guides the analysis, and gives a brief description of the data developed. Section IV gives our econometric results and Section $V$ concludes with an interpretation of the meaning and implications of these results. 
Appendix A provides a detailed discussion of the data set.

II. The Subminimum Wage for Full-time Students

In this section we describe briefly the nature of the student

subminimum provision in the Fair Labor Standards Act and set out the basic facts regarding current size of the program.

\section{The Law}

Section $14(\mathrm{~b})$ of the Fair Labor Standards Act currently provides that certain classes of employers subject to the minimum wage provisions of the Act are eligible to pay full-time students less than the minimum wage otherwise applicable in their establishments. The provisions of Section 14(b) are governed by Chapter 5, Part 519 of the Code of Federal Regulations of the Employment Standards Administration (ESA), Wage and Hour Division of the Department of Labor. The current scope of Section 14 (b) is delineated by the specific language of the Section, the ESA regulations, and the scope of the coverage of the minimum wage law itself.

From the ESA regulations, a "fu11-time student" (FTS) eligible for employment at the subminimum is defined as:

a student who receives primarily daytime instruction at the physical location of a bona fide educational institution in accordance with the institution's accepted definition of a full-time student.

The major classes of employers that are covered by the minimum wage law that may pay FTSs below the statutory minimum are: (1) retail and service industry establishments, (2) agricultural sector establishments, and (3) institutions of higher education. The differentlal provided for in this program has consistently been governed by the provision that the full-time student wage may not be less than $85 \%$ of the statutory minimum $3 /$ wage. 
Employers covered by the subminimum fall into one of three classes, each having different limits on the employer's use of the program. First, any employer may employ six or fewer FTSs. Second, certain employers may employ more than six FTSs, with the total number of hours of the FTS work force at the establishment not exceeding $10 \%$ of the total hours of all employees during any month. Finally, some employers are permitted FTS hours up to a specified percentage (exceeding 10\%) of total employee hours. Employers may be subject to a higher percentage limit if they demonstrate with records that in the year preceding the application for certification in the program, the proportion of student hours of employment to total hours of all employees exceeded $10 \%$ at this, or a comparable establishment. This proportion is nearly always based on the "practice of similar establishments" of the same employers, or other employers in the same industry rather than records from that particular establishment. Once a firm is in the over $10 \%$ category, it remains in that category regardless of program use.

Table 1, based on published data, shows that about $45 \%$ of retail and service establishments in the program are in the greater than $10 \%$ category. These establishments cover about two-thirds of all student subminimum hours, and include most large, multi-establishment companies which use the program. In establishments in the less than $10 \%$ category, $5 \%$ of hours worked are worked by students paid below minimum wage. In establishments in the greater than $10 \%$ category, the comparable fraction is $15 \%$.

The way the program operates establishments in any category are permitted to hire students at the subminimum up to the specified maximum fraction of hours (or up to six students), whereupon they would be obligated to pay additional students at the minimum wage. Companies can be expected to seek permits with specified maximums above their normal anticipated usage. This in fact appears to be the case. 
TABLE 1: ESTABLISHMENT USAGE OF THE STUDENT SUMINIMUM ${ }^{1}$

FISCAL YEAR 1979

Al1 Industries

1. 非 estab1ishment renewals

2. total hours ${ }^{2}$

3. FTS hours ${ }^{2}$

4. Ratio of 3 to 2

21,184

723,669

76,102

.105

Retail and Service -

A11 Categories

1. It establishment renewals

2. total hours

3. total FTS hours

4. Ratio of 3 to 2

20,082

705,196

72,568

.103

Retail and Service -

Over 10\% Category

1. \# establishment renewals

8,539

2. total hours

3. FTS hours

4. Ratio of 3 to 2

309,263

50,919

.165

Agriculture - Al1 Categories

1. \# establishment renewals

2. total hours

18,473

3. FTS hours

3,534

.191

4. Ratio of 3 to 2

Institutions of Higher

Education

1. \# establishment renewals

2. FTSs employed

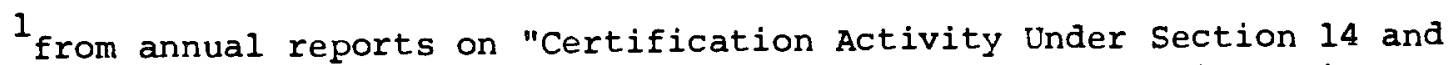
11 (d) of the FLSA," Department of Labor, Office of Administrative Management.

2 does not include institutions of higher education, for which these data are not collected. 
There are two other general restrictions on the hours FTSs may work that apply across the three different categories of FTS employers. Whether the employer is in the six or fewer, less than $10 \%$, or over $10 \%$ category, he must in some way meet the condition that the employment of FTSs at the subminimum wage "will not reduce the full-time employment opportunities of other persons". Generally, this requirement is satisfied by the employer attesting to this fact in his application. Since employment of FTSs serves as a substitute for other forms of labor, we regard this provision as a "dead letter". Secondly, there are hours restrictions for any individual FTS. While classes are in session an FTS may be paid the subminimum no more than 20 hours per week, and while classes are not in session the individual limit is 40 hours per week.

Establishments which violate the provisions of the act are liable to pay workers "back-pay" and instances of such orders can be cited.

In our discussion with Regional Administrators of the program, however, there was no case in which establishments were prosecuted for violating the nonsubstitution stipulation.

\section{Growth of the Program}

The FTS program began in 1961 as a result of concern about the possibly adverse effect on employment of students caused by the extension of the FLSA to an additionall. 3.6 million employees, most of whom were employed in retail or service establishments. The 1977 provisions described earlier are the result of several changes in the law, generally in the direction of encouraging use of the subminimum, the major exception being a 1966 decrease in the maximum hours FTS employees can work during the school year from that mandated in the initial legislation to 20 hours (see table 2). As a result of the changes in the law the number of certifications granted and students employed under this program has increased significantly. 
TABLE 2: CHANGES IN SUBMINIMUM WAGE PROVISIONS FOR STUDENTS

\section{Provision}

\section{1}

1. Establishment cannot employ FTSs more than $10 \%$ of total employment hours.

2. Maximum hours during school year is 24 .

3. Eligibility restricted to those 19 or less

4.

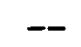

$\underline{1966}$

Some employers can employ FTSs more than $10 \%$ of total employment hours.
1974

Allows employment of up to 4 FTSs regardless of total employee hours in establishment.

Maximum hours reduced to 20 .

Remove age limit.

Agricultural establishments included.
Institutions of higher education included.
1977

Allows employment of up to 6 FTSs; eases reporting requirements for firms with 6 or fewer FTSs.

Source: U.S. Department of Labor. 
Columns 1-3 of Table 3 document the sizeable growth of the FTS program in the period covered. It shows a major jump in program usage in 1974-1975 and minor jumps in 1967 and 1978 as a result of the changes in the law in 1966, 1974 and 1977. The contraction in the extent of the program from 1976 to 1977 is in part due to the mid-1976 Supreme Court decision, National League of Cities vs. Usery, which held that state and municipal employees that were brought under the FLSA with the 1974 amendments should properly be exempt from minimum wage provisions. To get a notion of magnitude of the impact of the program on the student job market, population and labor force participation rates, column 3 gives estimates of total student employment. Roughly $3 \%$ of all student employment is accounted for by the program.

In sum, from modest beginnings the student subminimum has become a non-negligible part of the minimum wage system in the United States. While only a small proportion of employed students are paid the subminimum, In establishments using the program it is of sizeable import.

\section{Research Design and Data Description}

Employment of full-time student labor under the subminimum provision, like employment of other workers, is determined by demand and supply forces. Demand for FTS labor will depend on the cost of such labor relative to other inputs, the output of the firms with certificates, and the specific technological and institutional characteristics of the firms. Supply of FTS labor will depend on the alternatives available to students in the local labor market.

To analyze the demand and supply determinants of full-time student labor under the student subminimum one needs data on the number of FTS workers and on the various demand and supply factors. As there did not 
TABLE 3: USAGE OF THE FTS PROGRAM, FISCAL YEARS 1962 - 1979

\begin{tabular}{|c|c|c|c|}
\hline \multirow[b]{2}{*}{ Fiscal Year } & \multicolumn{2}{|c|}{ Program Usage } & Total Economy \\
\hline & Certificates 1 & Students ${ }^{2}$ & Student Employment ${ }^{3}$ \\
\hline 1962 & 2,344 & 10,700 & $3,562,000$ \\
\hline 1963 & 2,639 & 12,100 & $3,841,000$ \\
\hline 1964 & 2,639 & 14,000 & $3,933,000$ \\
\hline 1965 & 3.069 & 14,300 & $4,652,000$ \\
\hline 1966 & 2,596 & 11,900 & $4,914,000$ \\
\hline 1967 & 4,427 & 20,200 & $5,244,000$ \\
\hline 1968 & 4,784 & 21,900 & $5,616,000$ \\
\hline 1969 & 5,086 & 23,200 & $6,049,000$ \\
\hline 1970 & 4,981 & 22,800 & $5,967,000$ \\
\hline 1971 & 4,785 & 21,900 & $6,298,000$ \\
\hline 1972 & 4,576 & 20,900 & $6,472,000$ \\
\hline 1973 & 4,314 & 19,700 & $6,940,000$ \\
\hline 1974 & 7,551 & 76,300 & $7,040,000$ \\
\hline 1975 & 25,256 & 252,300 & $6,950,000$ \\
\hline 1976 & 21,110 & 438,800 & $7,245,000$ \\
\hline 1977 & 19,564 & 214,200 & $7,621,000$ \\
\hline 1978 & 31,931 & 304,500 & -- \\
\hline 1979 & 30,948 & 304,400 & -- \\
\hline
\end{tabular}

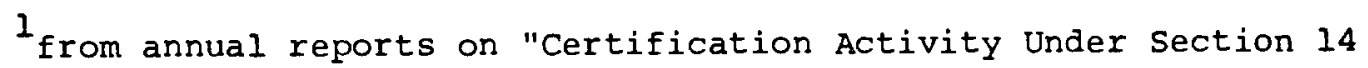
and $11(\bar{d})$ of the FLSA, " Departnent of Labor, Office of Administrative Management.

2 uses our estimate of 4.57 students per certificate except in higher education where the Department of Labor estimate of 292 is used. This number (4.57) differs irom tile standard jepartment of Labor estimate of 7.75 students per certificate because the Department of Labor estimate was based on 1 . 6 ? data for F?S hours wor!:ed and an outside estimate of the number of hours worked by an average student per year. Our estimate was based on more recent data concerning FTS hours worked and a survey of employers concerning hours worked per student per year.

3 U.S. Department of Labor, Employment and Training Report of the President, 1979, table B-7, P. 300 . 
did not exist, prior to our study a data set with the requisite information, we devoted a good deal of effort to obtaining the information needed for analysis of the student subminimum.

The primary sources of our data set are the administration records on employer application for certification under the program. As described in detail in the data appendix, we obtained a sample of 7,874 establishments from the administrative records, selecting those in companies that had ten or more establishments enrolled in the program and that were in the over $10 \%$ certificate class of users. We obtained information on the number of FTS hours and related information on these establishments for the period 1971-1978, as indicated in table 4.

The administrative records lacked information on the characteristics of companies, wages of non-FTS labor and other aspects of the local labor market in which an establishment is found. To obtain data on these determinants of FTS-labor we went to two other sources.

Data on the characteristics of the companies with FTs certificates we obtained by a telephone survey of the more than 200 parent companies to which our establishments belonged. As table 4 shows, we obtained information from the telephone survey on two key institutional factors which can be expected to influence employment of FTS labor, along with related variables: unionism and explicit corporate policy toward employment of FTS labor. We expect unionism to reduce usage of the FTS program, in order to protect the wage scale and jobs of covered labor. With respect to corporate policy we hypothesize that companies which either reward or pressure managers for cost reductions through employment of FTSs can be expected to hire more than companies which do not have such policies. Our questionnaire provides two pieces of information on corporate policy regarding FTS employment. The first piece of information deals with whether the company put any 
TABLE 4: SOURCES OF DATA ON THE SUBMINIMUM WAGE FOR STUDENTS

Source

Administrative Records

Telephone survey of companies

Published local labor market data

\section{Data}

- name of establishment

- total employee hours

- hours paid at subminimum in previous year

- full-time student employment as percent of total employment

- corporate incentives for establishments to hire FTS

- evaluation of labor market for workers at the minimum

- unionization of corporation

- average hours worked by nonFTS and FTS workers

- wages paid FTS workers and non-FTS workers on same job

- SMSA and state of establishment

- SMSA unemployment and manufacturing wages

- in 1969-1970: mean annual earnings of prime age (30-34) workers; of $16-19$ year olds;

- overall SMSA population 
pressures on the managers to use the program either through direct encouragement of program or managerial policies to hold down labor costs. The second asked whether the managers' compensation was in any way tied to their performance (profits, sales or costs). Using both of these measures, we hoped to account for different levels of company pressure on managers to cost minimize by using the program.

Information on local labor market conditions which might be expected to influence FTS employment, including the level of wages of potential substitute workers and the level of wages available to teenagers in an area we obtained from published sources. As our wage measures we took manufacturing wages in an area for the years covered from the BLS, and mean annual earnings for prime age (30-34 year old) workers and mean annual earnings for 16-19 year old workers for 1969, as reported in the Census of Population. Manufacturing wages have the advantage of being available on an annual basis; the Census data have the advantage of referring to the entire labor market and give us our only feasible measure of alternatives available to young as opposed to older workers. We also obtained data on area unemployment rates for the various areas.

We expect the area labor market variables to affect usage of students under the subminimum in accord with the demand-supply framework sketched out at the outset. Area wages (manufacturing average hourly earnings or prime age worker annual earnings) are expected to be positively related to the student subminimum hours as firms substitute students in favor of higher priced alternative labor. Area unemployment rates can be expected, by a similar logic, to have a negative effect on the employment of students at the subminimum. The higher the area unemployment rate, the greater is the likely availability of substitute labor and thus the less the incentive to employ the students. Finally the economic opportunities for teenagers in an area, reflected in the earnings of 16-19 year olds, 
is expected to influence employment of FTSs by altering the supply of students. The better the opportunities elsewhere the smaller will be the number accepting below minimum wage jobs.

The final result of the data collection is a data set containing over 20,000 establishment years from 1971 to 1979 with information on program usage (both hours worked and estimated number of students hired), local labor market conditions, and some data on the parent company.

Table 5 compares the size of our sample to that of the greater than $10 \%$ group from which the sample was drawn and to the total group of program participants from retail and service establishments. As can be seen, our sample includes about $30-40 \%$ of student hours in the greater than $10 \%$ group and $20-25 \%$ of all student hours in the industries covered. As retail and service trade represents $25 \%$ of all students hired under the program, our sample covers about $5 \%$ of the total FTs employment under the student subminimum.

Table 6 decomposes the 1978 observations in our sample by industry. What is important is the concentration of FTS bodies in department stores, who appear to be the major users of the program. The other important user is the variety, hardware, and drug store industry. It should be noted that this distribution relates only to establishments in our sample and thus to those in the greater than $10 \%$ category.

Analytic framework

While the data set has both time series and cross-section variation, in this study we focus exclusively on the cross-section variation. We do this for two reasons: first, because our company information and our information on the earnings of adult prime age and youth workers in a local labor market exist solely on a cross-section basis; second, because the limited years covered and the concurrence of changes in the minimum wage over the period covered and of changes in the provisions for the student subminimum makes it exceedingly difficult to determine the effect of changes in the minimum in a time series. Note that by focusing on the cross-sectional data we 

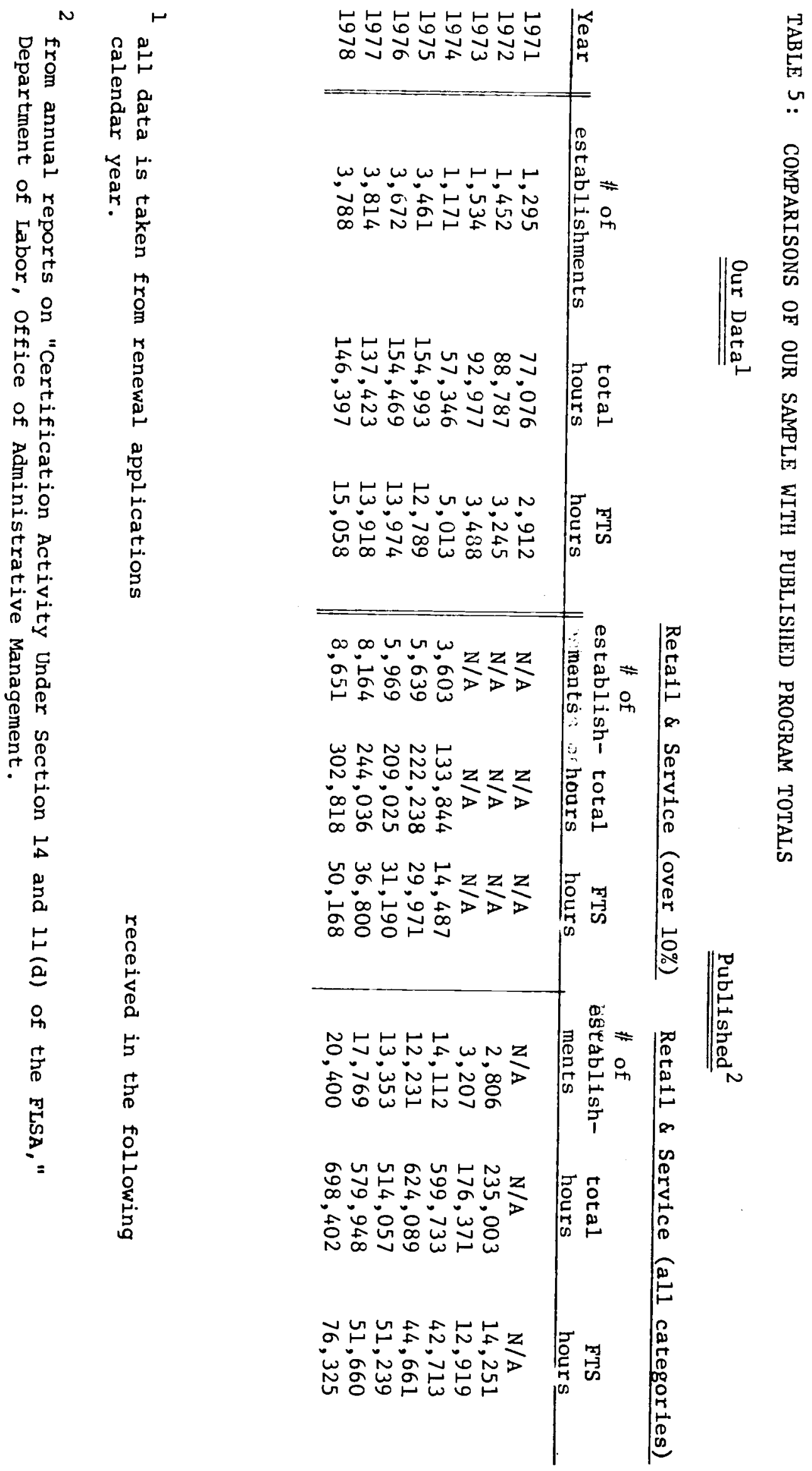
TABLE 6: DISTRIBUTION OF PROGRAM USAGE, BY INDUSTRY IN OUR SAMPLE 1978

\begin{tabular}{|c|c|c|c|c|c|}
\hline Industry & $\begin{array}{l}\text { Non-FTS } \\
\text { Workers }\end{array}$ & $\begin{array}{c}\text { FTS } \\
\text { Workers }\end{array}$ & $\begin{array}{l}\text { Total } \\
\text { Workers }\end{array}$ & $\begin{array}{l}\text { Percent Dis- } \\
\text { tribution of } \\
\text { FTS Workers }\end{array}$ & $\begin{array}{l}\text { Percentage of } \\
\text { Workers Who } \\
\text { are FTS }\end{array}$ \\
\hline Department Stores & 32,180 & 14,251 & 46,431 & .80 & .31 \\
\hline Variety, Hardware \& Drug & 26,279 & 1,872 & 28,151 & .10 & .07 \\
\hline Food & 5,748 & 895 & 6,643 & .05 & .13 \\
\hline Apparel & 1,773 & 502 & 2,275 & .03 & .22 \\
\hline Theater & 1,792 & 382 & 2,174 & .02 & .18 \\
\hline
\end{tabular}

Source: Our data set. 
eliminate most variation in the student subminimum itself: unless companies choose otherwise they pay $85 \%$ of the same minimum wage by the law. This does not, however, mean that we cannot make inferences about establishment responses to changes in the subminimum wage. Since labor demand decisions depend on relative factor costs and student supply decisions depend on comparisons of the subminimum with alternative wages, we can interpret coefficients on other wage variables as reflecting the impact of the fixed subminimum versus the variation in the other wages across areas.

A small formal model

To provide a more formal framework for ensuing analyses, let

$\mathrm{L}_{\mathrm{S}}=$ demand for FTS labor with corresponding elasticity of $\sigma$,

$S=$ supply of FTS labor with corresponding elasticity of $\varepsilon$,

$W_{S}=$ the fixed wage for students,

$\mathrm{X}=$ the level of demand curve for FTS labor,

$\mathrm{W}_{\mathrm{N}}=$ wage of non-FTS labor (proxied in our empirical analysis by the area manufacturing wage or average annual earnings of

.. prime' age workers) $y$ ' and

$\mathrm{L}_{\mathrm{N}}=$ non-FTS hours of employment.

Now let dots above variables reflect In derivatives, so that $\dot{L}_{s}$ and $\dot{S}$ are demand and supply changes respectively, and $\dot{\mathrm{W}}_{\mathrm{S}}=0$ (since the student wage is fixed). The relative demand for student labor can then be expressed as:
(1) $\dot{\mathrm{L}}_{\mathrm{S}}-\dot{\mathrm{L}}_{\mathrm{N}}=-\sigma\left(\dot{\mathrm{W}}_{\mathrm{S}}-\dot{\mathrm{W}}_{\mathrm{N}}\right)+\dot{\mathrm{X}}$.
i:
If supply factors do not constrain the employment of FTS workers, so that firms face an infinitely elastic schedule at the fixed price, $W_{s}$, and if output is fixed $(\dot{\mathrm{X}}=0)$, employment will be:

$$
\text { (2) } \dot{\mathrm{L}}_{\mathrm{S}}=\sigma \dot{\mathrm{W}}_{\mathrm{N}}+\dot{\mathrm{L}}_{\mathrm{N}}
$$


Equation (2) expresses an isoquant relationship for the trade-off between two factors of production, FTS labor and non-FTS labor, given a constant elasticity of substitution between the two, where the "market" wage of the FTS input is held fixed at the subminimum.

When the availability of students at $\mathrm{W}_{\mathrm{S}}$ is insufficient to meet demand, the analysis is more complex as supply factors will also enter the employment determination equation. Thereiare two basic ways in which to model this situation: in the first, the supply constraint is assumed to be effective, at least in some labor markets, so that firms are unable to hire the number of students desired at the subminimum; in the second, certain nonwage costs and adjustments are assumed to equilibrate the market.

Panel A of figure 1 depicts the first situation. In the region where supply and demand cross before the fixed subminimum wage $\left(\overline{\mathrm{W}}_{\mathrm{S}}\right)$, the supply constraint produces employment below that predicted by the demand curve. In the region where the schedules cross after $\vec{W}_{S}$, by contrast, employment is determined by the demand model (1) and (2). With a national minimum, it is likely that in some markets establishments will be supply constrained whereas others will not be so constrained, depending on the earnings opportunities available to students outside the subminimum sector.

Panel B represents what we believe to be a more realistic model, in which firms may respond to supply constraints through either raising the subminimum or engaging in costly search for students (which shifts the supply curve) or in reducing hiring standards. With respect to the first form of adjustment, while the majority of the thirty-nine companies responding to question $11 \mathrm{~g}$ in the company survey ("Hourly Wage Paid to FTSs?") paid exactly $15 \%$ below the minimum wage, seven companies did indicate paying FTSs a wage that is below the federal minimum yet greater than $85 \%$ of the minimum wage. 


\section{FIGURE 1}

Demand and Supply for FTS Labor

A. Model with Constraints

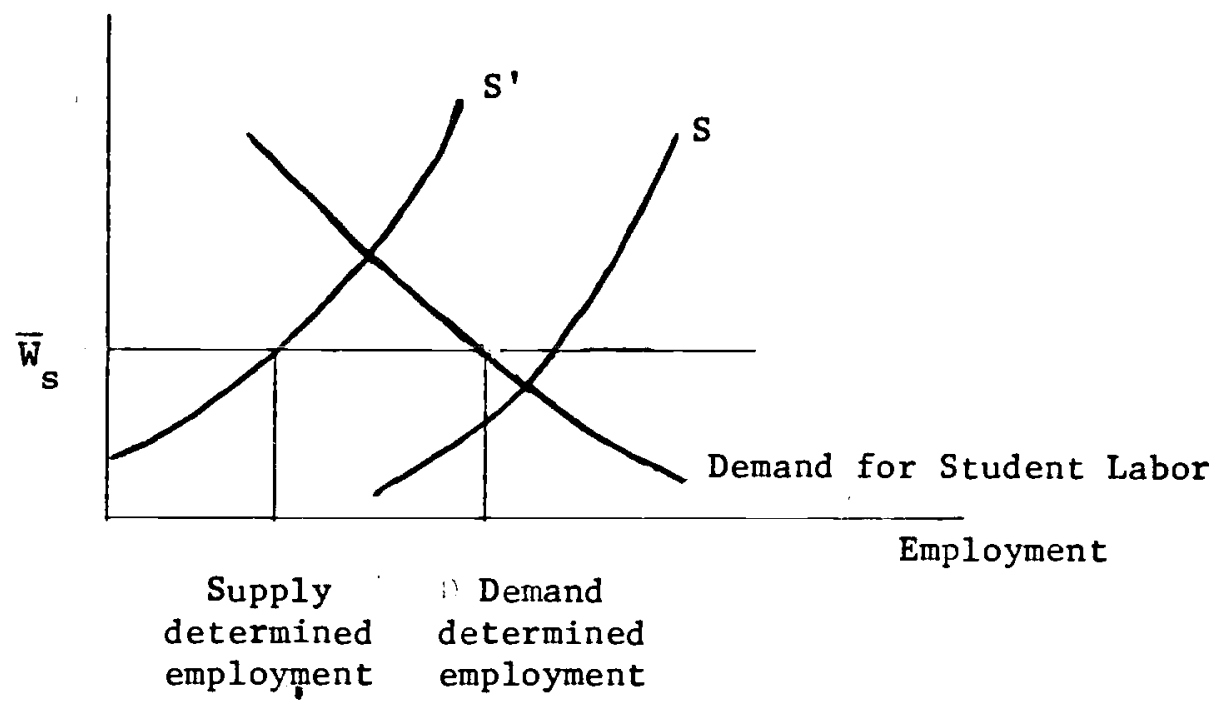

B. Model with Non-Wage Costs and Adjustments

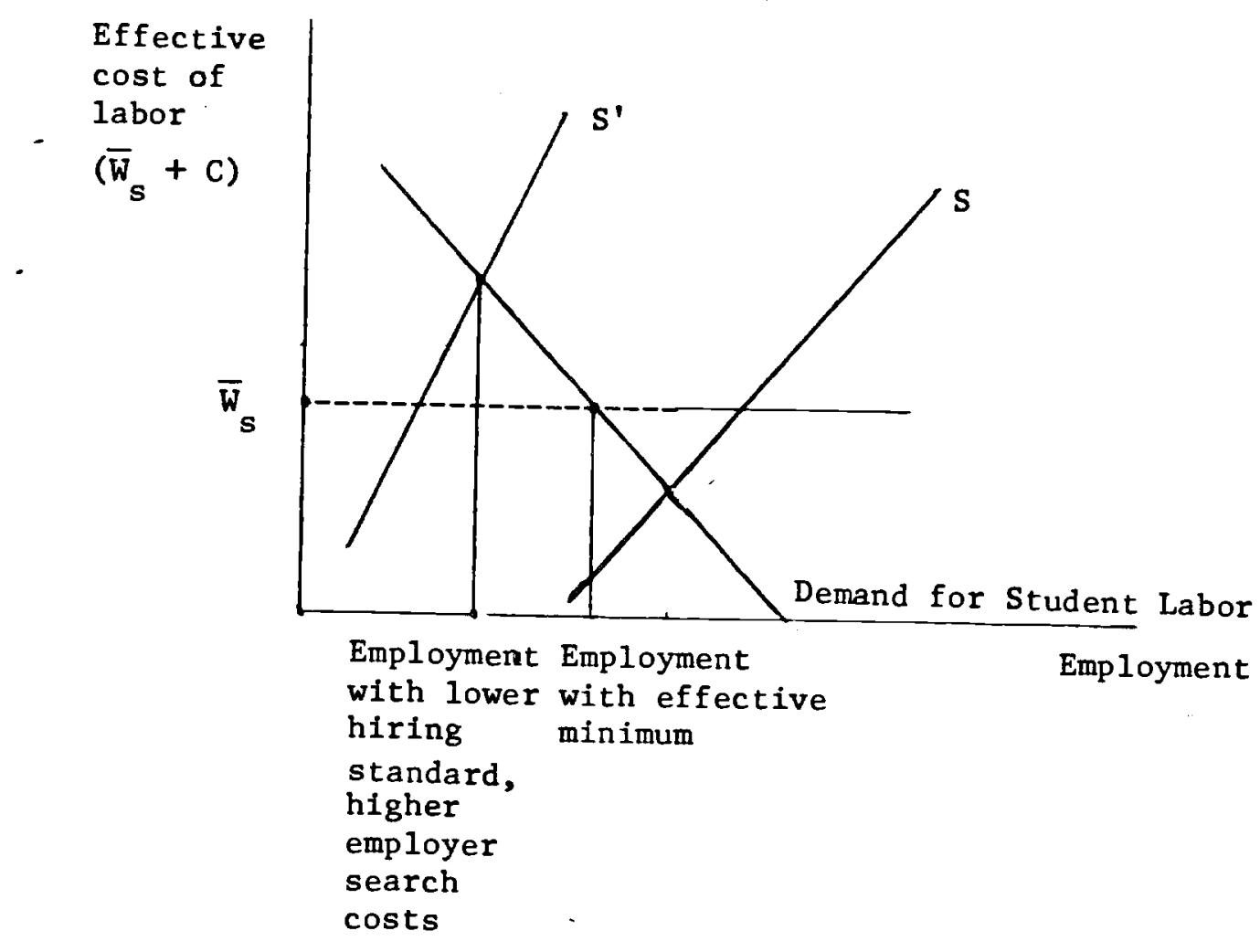


Another response is to continue to hire students but to pay them at or above the minimum wage. Student employees then move into the category of non-FTS labor. If the employer does not differentiate in the wages paid to students and responds to a supply constraint in this manner, he will either report no FTS hours of employment under the program or drop out of the program altogether. While our sample is not designed to examine the latter possibility, 28 percent of the establishment years included in the sample are from establishments enrolled in the program but without any student hours of employment paid at subminimum wages. For such establishments that have invested in enrolling in the program, but have no FTS hours of employment, we expected measures of student supply to be particularly important considerations.

A third response for employers is to invest more resources in locating student labor willing to work at the subminimum wage. In this way, the cost of student labor facing employers consists of two components: the dollars paid to the FTS labor and the incremental costs incurred by employers to locate this labor.

Whichever response dominates, the implication is that supply factors will also influence $L_{s}$. The cost of student labor will adjust to market conditions in such a way as to influence employment of FTSs.

We model this situation by adding an additional cost term to our demand equation: $\quad C=$ cost of student labor above and beyond $\bar{W}_{S}$. Our new demand curve is:

(3) $\dot{\mathrm{L}}_{\mathrm{s}}=-\sigma\left(\dot{\mathrm{C}}+\dot{\mathrm{W}}_{\mathrm{s}}-\dot{\mathrm{W}}_{\mathrm{N}}\right)+\dot{\mathrm{L}}_{\mathrm{N}}+\dot{\mathrm{x}}=-\sigma \dot{\mathrm{C}}+\sigma \dot{\mathrm{W}}_{\mathrm{N}}+\dot{\mathrm{L}}_{\mathrm{N}}+\dot{\mathrm{X}}$

On the supply side, we make the supply curve of students depend on the subminimum alternative earnings, and the additional cost factor:

$$
\text { (4) } \dot{\mathrm{L}}_{\mathrm{s}}=\varepsilon\left(\dot{\mathrm{W}}_{\mathrm{s}}+\dot{\mathrm{C}}-\dot{\mathrm{W}}_{\mathrm{y}}\right)=\varepsilon \dot{\mathrm{C}}-\varepsilon \dot{\mathrm{W}}_{\mathrm{y}}
$$

where $w_{y}=$ alternate wage students can earn (proxied in the empirical work by the mean annual earnings of all 16 to 19 year olds in the SMSA for those reporting earnings), 
and where the elasticity of supply to all the relevant costs and wages is assumed the same. Solving equations (3) and (4) yields the following equation for the differential number of FTS students hired.

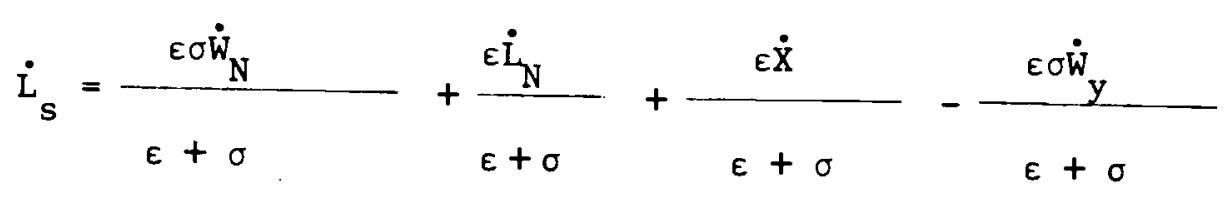

Equation (5) is overidentified with respect to $\varepsilon$ and $\sigma$ given outside estimates of $\dot{X}$ and the correct estimates of $\dot{\mathrm{W}}_{\mathrm{N}}$ and $\dot{\mathrm{W}}_{\mathrm{y}}$. This can be seen by noting that separate estimates of $\sigma$ are derivable by dividing the coefficient on $\dot{W}_{N}$ by the coefficient on $\dot{L}_{N}$ (or $\dot{X}$ ) or by dividing the coefficient on $\dot{W}_{y}$ by the coefficient on $\dot{\mathrm{L}}_{\mathrm{N}}$ (or $\dot{\mathrm{X}}$ ). According to the model the coefficients on $\dot{\mathrm{W}}_{\mathrm{N}}$ and $\dot{\mathrm{W}}_{\mathrm{y}}$ should be identical. Because our estimates of $\dot{\mathrm{X}}$ refer to potential factors altering the level of demand (unionism, for instance) and only the crudest categorization of sales, we will focus on the ratio of the relevant coefficients to that on $\dot{\mathrm{L}}_{\mathrm{N}}$ in the analysis.

IV. Econometric Analysis of Participation and Use of Student Subminimum

This section presents the statistical results of our analysis of our establishment data set. The analysis shows that consistent with our model, employment depends on both the demand and supply side forces in the local labor markets. The impact of wages of other workers on employment of FTSs is positive but is extremely sensitive to changes in the specification of the employment equation. Average teenage earnings have a sizeable negative impact. Area unemployment also has a negative impact on FTS employment. We also find that several establishment characteristics influence employment of FTSs, with unionized establishments in particular using relatively less FTS labor than other establishments. Establishments whose companies actively encourage their establishments to use the program show greater usage, though more general incentives to cut costs or raise profits (such as profit sharing plans) did not increase program use. These same factors determine both whether or not an establishment uses its permit and the FTS employment among users. 
Analysis

We analyze the effect of explanatory variables on program usage using two samples from our establishment data set: a sample consisting of all establishments, including those that do not have any FTS students, and a sample restricted to establishments that in fact use their permits. Within each sample we also analyze a subsample consisting of those establishments in SMSAs for which we had local labor market information from the 1970 Census. With the all-establishment sample, we analyze the number of FTS hours worked and the ratio of FTS to non-FTS hours worked, without correcting (say via a Tobit analysis) for the fact that a significant number of observations are clumped at zero hours. We also run linear probability and probit equations for whether or not an establishment in fact hires any FTS labor. With the sample of establishments which use some FTS labor, we estimate equations relating the in of FTS hours worked and the In of FTS hours divided by non-FTS hours worked to the dependent variables.

For several of the variables from our company survey, there were a sizeable number of missing observations. Rather than deleting observations and running into problems of sample selectivity due to missing observations, we included special dumny variables for missing observations. As we have done this only for variables that are categorical, we are simply establishing a new category and thus face no major econometric problems as a result.

In addition to the variables discussed in the previous section, we include three other sets of "controls". First, we controlled for year, as changes in the law might affect program use. Second, we controlled for industry (e.g., theatre and food store), to hold fixed for technological differences in the ability to utilize the program. Third, we controlled for the region in which an establishment was located. Initially, we anticipated region would be an innocuous variable but it turned out to have an important effect in one set of calculations, for reasons we do not understand. 


\section{Results: Determinants of Student Hours in Full Sample}

The major results of the econometric analysis are given in Table 7 which records the results of least squares regression of FTS hours on the postulated determinants. These results are reported for the entire sample of establishments, including those which lack some information about the local labor market. Columns 1-4 report calculations using average hourly earnings in manufacturing as the indicator of the cost of substitute labor in the area while columns 5-6 report calculations using the annual earnings of prime age workers as the indicator of the cost of substitute labor. As the calculations include some establishments with zero FTS hours, we do not use the log transformation of the dependent variable. The basic model includes establishment characteristics and demand side variables. To these are added supply side variables, as well as controls for Census region.

The first set of explanatory variables tested are designed to identify the establishments' demand for FTS labor. As can be seen from the first lines of the table, a higher manufacturing wage rate increases program use, and a higher area unemployment rate lowers program use. As the area wage rises and unemployment falls, it becomes more expensive to hire regular workers because they are no longer available at the minimum wage. If the alternative, better paying jobs are not open to fulltime students, they may still be willing to work at the subminimum. Thus, the price of student labor has fallen relative to regular labor, and more student labor will be used implying that student labor is a good but far

from perfect substitute for non-student labor. Note, however, the significant variation in the magnitude of the estimated wage effect, depending on the inclusion of regional controls: without region, the coefficient on $\log$ wage with manufacturing hourly earnings is on the order of 2.1 
TABIE 7: ESTIMATES OF THE DETERMINANTS OF FULL-TIME STUDENT HOURS BY ESTABL ISHMENT: FULL SAMPLE AND SMSA SUBSAMPLE, 1971-1978

Dependent variables: full-time student hours

Full Sample mean $=3.492 ;$ s.d. $=4.866 ; \mathrm{N}=20,127$

SMSA Subsample mean $=4.147 ;$ s.d. $=5,320 ; N=11,541$

Regression Coefficients and Standard Errors on Explanatory Variables

Full Sample

Mean (S.D.)

(1)

Full Sample

Demand Side Factors

Log wage in area

1.60

(.23)

2.62

(2)

(3)

(4)

Log prime age annual

earnings in SMSA

8.86

Predicted log prime age

annual earnings in SMSA

(.07)

Unemployment in area

1.71

(.01)

(2. 20)

Non-FTS hours

41.6

(48.2)

(.21)

2.09

.82

(.21)

$(.27)$

.35

(.27)

Establishment Annual Sales

Under $\$ 250,000$

.21

$\$ 250,000$ to $\$ 1,000,000$

Missing data

.29
7.20

$(.07)$

13.4
Log population in SMSA

Log teenage annual

earnings in SMSA

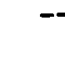

$-$

$$
\begin{aligned}
& -.06 \\
& (.02)
\end{aligned}
$$

.0029

$(.0007)$

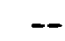

$-$

$-.09$

$-.06$

$(.02)$

$-.09$

.0029

$(.0007)$

.0033

$(.0007)$
$(.02)$

.0033
$(.0007)$

\section{Supply Side Factors}

$\begin{array}{cccc}-1.75 & -1.68 & -1.50 & -1.44 \\ (.12) & (.11) & (.12) & (.12) \\ -.86 & -.80 & -.80 & -.75 \\ (.10) & (.10) & (.10) & (.10) \\ .20 & .25 & .38 & .41 \\ (.10) & (.10) & (.10) & (.10)\end{array}$

Institutional Factors

Some Company Employees are Union Mexbers

Missing data

Difficulty of finding

fisfakle Unskilied (Non-

$\frac{\text { Fisf Workers din. Wage }}{\text { Somewhat dificuit }}$

Very dificult

It varies

Missing data

Managers rewarded for Holding Down Payroll Costs by Hiring FTSs

Pressure (incentive) given to Managers to Use Program

Missing da $a$

Other Controls

Years

Industry

SMSA data missing

Region

Sumnary Statistics

MSE
$\mathbf{R}^{2}$
.21

.41

.02

.04

.31

.29

.47

.47

.35

-1.49
$(.12)$
-1.79
$(.16)$
-1.77
$(.23)$
1.59
$(.19)$
.46
$(.11)$
-.07
$(.37)$
-.19
$(.12)$
1.12
$(.11)$
.86
$(.10)$
7
6
2
0

16.41 .308
$-1.59$

(.12)

$-1.65$

(.13)

$-1.71$

$-1.82$

$-1.62$

(.16)

(.16)

$-1.64$

(.16)

$-1.78 \quad-1.61 \quad-1.61$

(.22)

(.23)

(.23)

1.53

1.52

(.19)

1.46

(.19)

.62

(.50

(.11)

(.19)

.65

(.11)

$-.04$

.07

.06

(.36)

(.37)

(.37)

$-.20 \quad-.18$

-.18
$(.12)$

$-.19$

(.12)

(.12)

$\begin{array}{lll}1.15 & .98 & 1.02\end{array}$

(.11)

(.11)

(.11)

.82

.61

.58

(.13)

(.18)

(.18)

\section{7}

6

2

7

6
2

3

7

6

2

$\begin{array}{ccc}16.26 & 16.31 & 16.17 \\ .314 & .313 & .318\end{array}$


TABLE 7 (cont.)

Regression Coefficlents and Standard Errors on Explanatory Variables

\section{(5)}

Full Sample

(6)

SMSA Subsample

(7)

(8)

\section{Demand Side Factors}

Log wage in area

Log prime age annual earnings in SMSA

Predicted log prime age annual earnings in SMSA

Unemployment in area

Non-FTS hours

Establishment Annual Sales

Under $\$ 250,000$

$\$ 250,000$ to $\$ 1,000,000$

Missing data

Supply side Factors

Log teenage annual earnings in SMSA

Log population in SMSA

Institutional Factors

Some Company Employees are Union Members

Missing data

Difficulty of Finding Reliable Unskilled

(Non-FTS) Workers Minimum Wage

Somewhat difficult

Very difficult

It varies

Missing data

Managers Rewarded for Holding Down Payroll Costs by Hiring FTSs

Pressure (incentive) given to Managers to Use Program

Misaing data

Other controls

Years

Industry

SMSA data missing

Region

Summary statistics

$\begin{array}{llll}-- & -- & -- & -- \\ -- & -- & 8.08 & 4.93 \\ & & (.49) & (.82) \\ 6.76 & 1.77 & -- & -- \\ (.53) & (1.40) & & \\ -.04 & -.07 & -.05 & -.09 \\ (.02) & (.02) & (.03) & (.03) \\ .0029 & .0032 & .0033 & .0035 \\ (.0007) & (.0007) & (.0009) & (.0009)\end{array}$

$\begin{array}{cccc}-1.72 & -1.48 & -1.86 & -1.73 \\ (.12) & (.12) & (.17) & (.17) \\ -.86 & -.78 & -.51 & -.44 \\ (.10) & (.10) & (.14) & (.14) \\ .37 & .39 & .63 & .62 \\ (.10) & (.10) & (.14) & (.15)\end{array}$

$\begin{array}{cccc}- & -2.67 & - & -3.02 \\ - & (.56) & & (.66) \\ & .58 & -- & .45 \\ & (.08) & & (.07)\end{array}$

$\begin{array}{cccc}-1.70 & -1.73 & -1.27 & -1.44 \\ (.12) & (.13) & (.18) & (.19) \\ -1.95 & -1.70 & -1.20 & -1.25 \\ (.16) & (.17) & (.25) & (.26)\end{array}$

-1.7
$(.23)$

$-1.62$

$-1.07$

$-1.05$

1.53

(.19)

(.23)

(.32)

(.32)

1.47

(.19)

.91

.87

.51

(.11)

.62

(.24)

(.24)

.003

(.11)

.71

.79

(.36)

.05

(.16)

(.16)

(.36)

(.37)

$-.43$

$-.33$

-.20
$(.12)$

$-.19$

.

(.51)

(.12)

$-.58$

$-.61$

1.10

1.03

(.17)

(.17)

(.11)

(.11)

1.22
$(.16)$

1. 22

.80

.59

.17

(.26)

(.16)

(.18)

(.18)

7

7
6
2
3

7
6
2
0

$\begin{array}{llll}7 & 7 & 7 & 7 \\ 6 & 6 & 6 & 6 \\ 2 & 2 & 2 & 2 \\ 0 & 3 & 0 & 3\end{array}$


to 2.6 ; with region, the coefficient drops to .35 to .82 , significant given the number of observations but considerably smaller. In the calculations using the prime age earnings in the SMSA the results are quite different. In a sample consisting solely of establishments for which Census SMSA data are available we obtain comparable earnings coefficients with and without region controls. In the full sample where we "filled" in the missing earnings by instrumenting the prime age earnings on the manufacturing earnings, we obtain large coefficients but here the magnitude drops noticeably with the addition of region controls. We tried to find an explanation for the significant region effects, (the coefficients showed that employment of the FTS labor is greater in the North Central, followed by the West, and is least in the South) but failed. We do not have a satisfactory explanation for this or for why the area manufacturing wage is so sensitive to it.

The results with our supply side indicator of alternative earnings available to young workers are more stable, with the teenage earnings variable obtaining coefficients on the order of -2.1 to -3.0 in all cases. In the model presented in the previous section, the coefficient on the teenage earnings should be similar to that on the cost of substitute labor, and this is the case in some but not all of the calculations, as can be seen in the table.

Considering establishment (and company) characteristics, the major determinant of program usage is unionization, which, as expected, greatly reduces usage. Smaller establishments (measured on annual sales) also use less FTS labor, which is also expected. On the other hand, variables to control for difficulty in finding non-FTSs at the minimum do not work well, with no clear pattern emerging.

The results from the analysis of company policies designed (or expected) to encourage program use suggest that only policies directed at the FTS program itself are effective in raising usage. General policies 
to reward good performance, through bonuses or promotion, tend if anything to reduce usage when introduced along with variables measuring direct encouragement. One possible explanation is that companies may set up these plans, but not have them perceived by the managers. Some support for this is found in our limited sample of establishment data; in cases where establishment managers said there was no link between their compensation and performance as managers, $45 \%$ of the company representatives had said there was such a link. Similarly, $25 \%$ of the company representatives said they pressured managers to use the program when the establishment managers had reported no such pressure.

Finally, the establishment managers may pursue goals other than maximum profits: if they prefer working with non-students they may not hire FTSs, even if hiring FTSs would reduce labor costs and increase profits.

Determinants of Whether an Establishment Uses Its Permit or Not

Because a sizeable number of establishments which can hire FTSs do not do so, it is of interest to examine the factors that influence whether a company uses its permit, as well as the total FTS hours. Accordingly, we have estimated linear and probit probability models designed to explain use of permits.

The linear probability analysis is given in columns $1-3$ of Table 8 ; the probit analysis is given in columns 4-6. Both sets of equations yield results consistent with those given earlier. Column 7 shows what happens when the linear analysis is done for the SMSA subsample, using the log prime age earning variable, rather than the area wage. Most independent variables obtain qualitatively similar coefficients to those in Table 7, as higher unemployment rates, higher teenage earnings, and unionism all discourage usage, while pressure to use the program encourages usage. It is perhaps more instructive to focus on the differences between these results and those of Table 7 . First, once region controls are entered, the BLS manufacturing wage has no 
TABLE 8: LINEAR PROBABILITY AND PROBIT ANALYSES OF WHETHER AN

ESTABLISHMENT USES ITS FTS PERMIT

Dependent variable: $1=$ use; $0=$ not use; mean $=.72 ;$ s.d. $=.45$

Full sample: mean $=.72 ;$ s.d. $=.45 ; \mathrm{N}=20,127$

SMSA Subsample: mean $=.74 ;$ s.d. $=.44 ; \mathrm{N}=11,541$

Full Sample

SMSA Subsample Linear Probability Probit

\section{(1)} (2)

(3)

(4)

(5)

Linear Probability

(7)

\section{Demand Side Factors}

Log wage in area

$\begin{array}{llll}.11 & .12 & -.01 & .48 \\ (.02) & (.02) & (.03) & (.07)\end{array}$

.54

$-.08$

Log prime-age annual

earnings in SMSA

$-$

Unemployment in

area

$$
\begin{array}{lllllll}
-.003 & -.003 & -.01 & -.01 & -.01 & -.03 & -.007 \\
(.002) & (.002) & (.002) & (.007) & (.007) & (.01) & (.003) \\
-.0024 & -.0024 & -.0023 & -.007 & -.007 & -.007 & -.0024 \\
(.0001) & (.0001) & (.0001) & (.0002) & (.0003) & (.0003) & (.0001)
\end{array}
$$

Non-FTS hours

Supply Side Factors

Log teenage annual earnings in SMSA

$$
\begin{array}{lll}
-.56 & -.39 & -- \\
(.05) & (.05)
\end{array}
$$

\begin{tabular}{|c|c|c|}
\hline-- & $\begin{array}{l}.02 \\
(.005)\end{array}$ & $\begin{array}{l}.02 \\
(.005)\end{array}$ \\
\hline
\end{tabular}

$$
-1.55
$$

(.20)

$$
-.45
$$

$\begin{array}{ll}.07 & .05 \\ (.02) & (.02)\end{array}$

$$
\begin{array}{r}
-.0002 \\
(.006)
\end{array}
$$

\section{Institutional Factors}

Some Company Employees are Union

Members

Missing data

Other controls

\section{Establishment}

$$
\begin{array}{llll}
-.29 & -.31 & -.37 & -1.07 \\
(.01) & (.01) & (.01) & (.05)
\end{array}
$$$$
-1.13
$$$$
(.05)
$$$$
-1.28
$$$$
\text { (.05) }
$$$$
-.65 \quad-.58
$$$$
(.06)
$$$$
(.06)
$$

annual sales

Difficulty of

finding workers

Managerial

incentives

Years

Industry

SMSA Data Missing

Region

\section{3}

4

3
7
6
2
0

Summary Statistics

MSE

$\mathrm{R}^{2}$

-2 In likelihood

Ratio

$\begin{array}{lllllll}.151 & .150 & .147 & -- & -- & -- & .136 \\ .259 & .264 & .277 & -- & -- & -- & .294 \\ -- & -- & -- & 5640 & 5740 & 6015 & --\end{array}$


significant impact on usage, suggesting a smaller role for alternative cost factors here. However, the prime age earnings used in the column 7 equation shows a significant impact on wage in the presence of region controls, just as it did in Table 7 . In addition, the impacts of unionization and teenage earnings are larger here when compared to the impacts of other variables than they were in the results presented in Table 7 . This is appropriate as these variables measure constraints (one institutionaland one supply-oriented) on the establishment's ability to find and hire FTSs.

In short, while there are some differences in the magnitude of impacts, the same set of variables affect the $0-1$ program use as affected overall hours with the same sensitivity of the coefficient on manufacturing wages to inclusion of regression controls.

\section{Determinants of Student Hours: Users Sample Only}

We turn next from analysis of the entire sample of establishments to the roughly $3 / 4$ ths who in fact use their permits and employ student labor at below minimum wage. For this sample our dependent variables are estimated in natural logarithms, which makes it easier to read off the elasticities on which economists focus. The results of these calculations are summarized in Table 9.

The results from column (1) indicate that without supply or region controls a sizeable impact of area wage on FTS employment is found, indicating a demand elasticity on the order of .6 to .7. Controls for supply do not change the result appreciably, but region controls do reduce the estimated elasticity to about .1. Without any explanation for the impact of regional controls, we are left with two rather different estimates. When we recalculate the estimates using the annual earnings of prime age workers for the area wage variable, we obtain the results in columns 3 and 4. Similar to the results of Table 7 , the impact of this measure on FTS employment is greater than the impact of area manufacturing wage. 
TABLE 9: DETERMINANTS OF LN FULL-TTME STUDENT HOURS AND LN (FULL-TIME STUDENT HOURS/NON-FULL-TIME STUDENT HOURS): USER'S SAMPLE AND SMSA USER'S SAMPLE

Dependent variable: In FTS Hours $\quad$ in $\left(\frac{\text { FTS Hours }}{\text { Non-FTS Hours }}\right)$

\begin{tabular}{|c|c|c|c|c|}
\hline Sample: & Fu11 User & SMSA User & Fu11 User & SMSA User \\
\hline & (1) (2) & (3) & (5) & \\
\hline $\begin{array}{l}\text { Mean } \\
(\text { S.D., N) }\end{array}$ & $\begin{array}{l}1.05 \\
(1.08,14428)\end{array}$ & $\begin{array}{l}1.22 \\
(1.08,8563)\end{array}$ & $\begin{array}{l}-2.13 \\
(1.16,14428)\end{array}$ & $\begin{array}{l}-1.97, \\
(1.16,8563)\end{array}$ \\
\hline
\end{tabular}

Demand Side Factors

$\begin{array}{llllll}\text { Log wage in area } & .67 & .06 & - & -- & .78 \\ (.05) & (.07) & & & (.06)\end{array}$

Log prime-age annual earnings -- --

in SMSA

(.12) (.19)

Log non-FTS

$.48 \quad .48$

hours

$(.01)(.01)$

$.48 \quad .48$

$(.02)(.02)$

1.0

1.0

Supply Side Factors

Log teenage

annual earnings -- -.75

in SMSA

$--1.01$

(.19)

Other Controls

Unemployment in area

11

$1 \quad 1$

1

1

Establishment annual sales

33

33

3

3

Log SMSA population

Union employees

$\begin{array}{ll}0 & 1 \\ 2 & 2\end{array}$

$\begin{array}{ll}0 & 1 \\ 2 & 2\end{array}$

0

0

Difficulty of finding workers

Managerial incentives

Years

Industry

SMSA data missing

Region

44

4

4

Summary Statistics

$$
\text { MSE }
$$


As the coefficients on the other variables are similar to those in previous tables, no further discussion of them is needed.

Finally, columns 5 and 6 turn to the determinants of the 1 n of the ratio of FTS to non-FTS hours with supply variable excluded, which brings us closer to the elasticity of substitution concept in models (1) and (2). The results here are quite similar to those in which we allow the coefficient on 1 n non-FTS hours to diverge from unity in the previous columns.

\section{Reconciling estimates}

The preceding statistical analyses yield relatively strong and similar results across regressions for all but one of the variables studied. Unfortunately, the variable for which results were not stable is the substitute wage variable: the manufacturing area wage falls sharply with inclusion of regional controls, while the prime-age earnings variable obtains consistently higher coefficients. As a result we have sets of estimates of the effect of the cost of substitute labor on employment of FTS workers which range from quite large to relatively modest. In terms of our full model (Section IV, equation 5), the coefficient on the log earnings of the teenagers should be the same as that on the wage variable. It generally falls between the estimated coefficients for the other two wage series, and varies less with the inclusion of region controls. This suggests that constraining the coefficient on teenage wage to be equal to that on adult wage might be appropriate. The results from this constrained estimation are presented in Table 10.

As expected, we find much less sensitivity to the inclusion of region controls with the constraint. The constraint also does not substantially affect the coefficients on the other variables, which are not discussed here. Looking at the full model from Section IV again, we see 
TABLE 10: DETERMINANTS OF PROGRAM USAGE, WITH WAGE COEFFICIENTS CONSTRAINED TO BE EQUAL

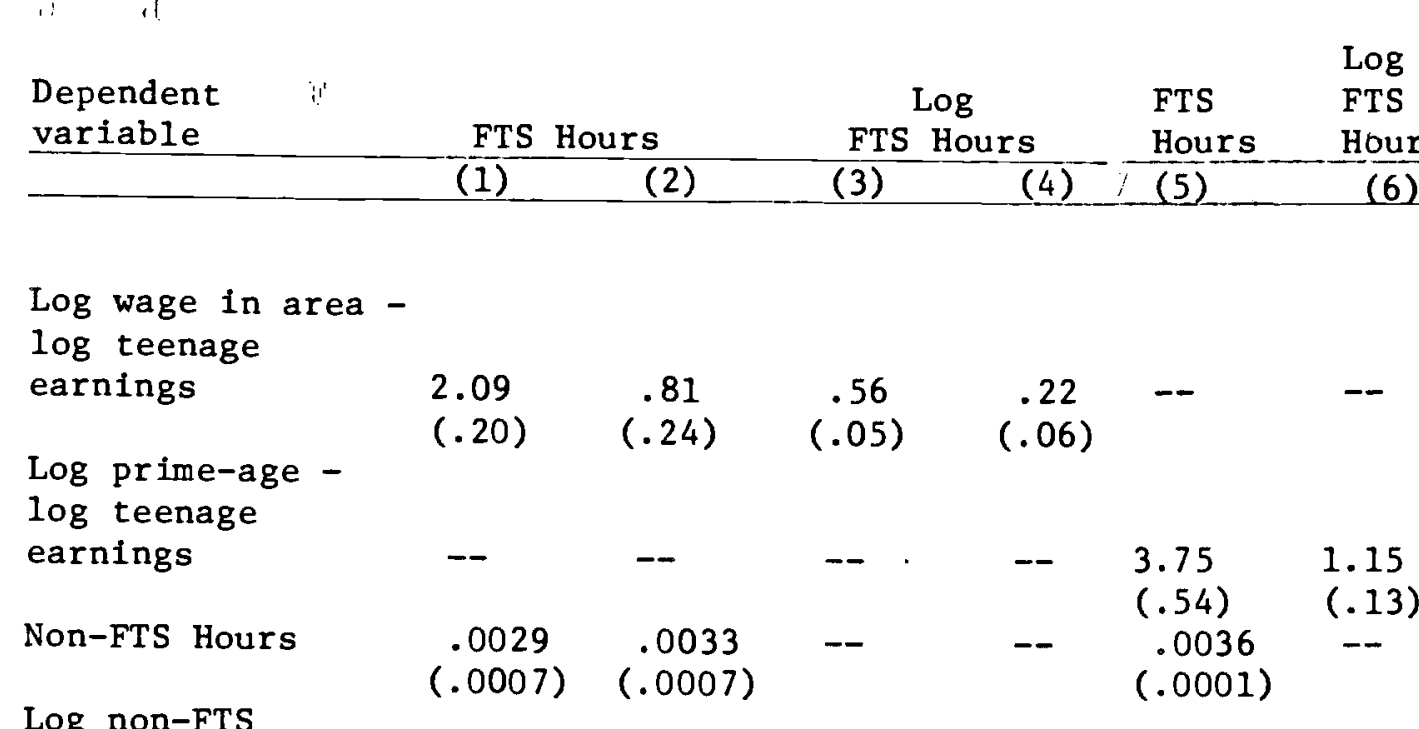

Hours

$--$

Other Controls

$.47 \quad .48 \quad--$

$(.01) \quad(.01)$

Unemployment in

area

1

1

1

11

1

Establishment

annual sales

3

3

3

33

3

Log SMSA

Population

Union employees

$1 \quad 1$

1

1

11

1

2

2

22

2

Difficulty of

finding workers

$\begin{array}{llllll}4 & 4 & 4 & 4 & 4 & 4\end{array}$

\section{Managerial}

incentives

3

3

3

33

3

Years

7

7

7

Industry

6

6

6

77

7

SMSA data

missing

2

2

2

$6 \quad 6$

6

Region

0

3

0

20

0

Summary Statistics

$\begin{array}{lrrrrrr}\text { MSE } & 16.26 & 16.18 & .704 & .699 & 19.83 & .718 \\ \mathrm{R}^{2} & .314 & .318 & .400 & .405 & .301 & .386 \\ \mathrm{~N} & 20137 & 20137 & 14428 & 14428 & 11541 & 8563\end{array}$

Note: Columns 3, 4, 6 are restricted to establishments with non zero FTS hours as in Table 9. 
that the demand elasticity may be calculated as the ratio of the wage coefficient to the coefficient on non-FTS hours. Using the manufacturing wage as our wage figure we obtain from column 3, which excludes region controls, a substitution elasticity of $1.2(.56 / .47)$; from column 4 we estimate an elasticity of $.46(.22 / .48)$. With the prime age earnings measure and region controls, we get a figure of $2.4(1.15 / .48)$. Although the estimates we have obtained are somewhat sensitive to region controls and sample changes, we conclude that there is a definite response of FTS employment to the wages of substitute labor, with the elasticity likely to fall between .5 and 1 . Implications

Given the estimates in Section IV, what can be said about the impact of the student subminimum on hours worked by the covered group? What can be said about the impact of the student subminimum on hours worked by non-FTS workers?

If we are willing to accept the supply and demand model of equation (5), we can at least get a crude notion of the elasticity of substitution between FTS labor and other labor and thus of the impact of the program. In this section we so interpret the estimated response parameters and use them to evaluate the impact of the program on hours worked by the two

groups. Our calculations suggest that the subminimum for students has generated FTS hours at eligible firms. Our calculations also suggest that the subminimum has reduced hours of non-FTS workers. The exact magnitude of this effect depends critically on the model used to determine the effect-specifically whether or not region variables are included in the analysis and the variable usedilto measure area wages.

Since the scale effect of lower wages would be to increase employment, our estimates presumably understate the increase in FTS hours and overestimate the decrease in non-FTS hours. We use crude data on the scale effect to get an idea of the extent of this additional employment effect. 
Elasticity mode1

First, we express the linkage between the elasticity of substitution and the elasticity of demand for FTS and non-FTS labor for the case in which there are no supply constraints using the same notation developed for the models previously described:

(6) $\dot{\mathrm{L}}_{S}-\dot{\mathrm{L}}_{\mathrm{N}}=\sigma \dot{\mathrm{W}}_{\mathrm{N}}$ where output is fixed.

The production function can be written as:

(7) $\dot{\mathrm{Q}}=\alpha_{\mathrm{S}} \dot{\mathrm{L}}_{\mathrm{S}}+\alpha_{\mathrm{N}} \dot{\mathrm{L}}_{\mathrm{N}}+\alpha_{\mathrm{R}} \dot{\mathrm{R}}$,

where $Q=$ output

$R=$ all other inputs

$\alpha s=$ elasticities of inputs in production.

We assume that the market is sufficiently competitive that the as can be approximated by shares of inputs in cost. Assume other inputs are fixed. Then with output fixed:

(8)

$$
\dot{\mathrm{L}}_{\mathrm{S}}=-\alpha_{\mathrm{N}} / \alpha_{\mathrm{S}} \dot{\mathrm{L}}_{\mathrm{N}}
$$

Substituting (8) into (6) yields:

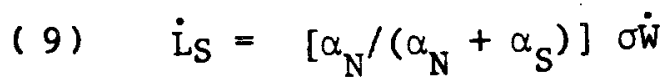

(10) $\quad \dot{\mathrm{L}}_{\mathrm{N}}=\left[\alpha_{\mathrm{S}} /\left(\alpha_{\mathrm{N}}+\alpha_{\mathrm{S}}\right)\right] \sigma \dot{\mathrm{W}}$

Equations (9) and (10) can be used to estimate the impact of wage changes due to the subminimum on hours worked of student and nonstudent labor, given estimated ratios of expenditures on the two forms of labor and estimated elasticities of substitution.

Table 11 contains the relevant information on the expenditures on the two types of labor estimated from our establishment survey. To estimate expenditures on FTS labor, we multiplied FTS hours by the subminimum wage. 
TABLE 11:: ESTIMATES OF EXPENDITURES ON FTS AND NON-FTS LABOR AND OF THEIR SHARES OF LABOR COST PER ESTABLISHMENT

\section{ENTIRE SAMPLE}

All Years 1978

FTS Labor

$\$ 6,602$

$\$ 8,968$

Non-FTS Labor

$\$ 141,444$

$\$ 149,743$

FTS Share of Labor Cost

.04

.06

iNon-FTS Share of Labor Cost

.94

\section{USERS SAMPLE}

\begin{tabular}{ll} 
A11 Years & 1978 \\
\hline
\end{tabular}

FTS Labor

$\$ 9,209$

$\$ 11,906$

Non-FTS Labor

$\$ 112,470$

$\$ 109,570$

FTS Share of Labor Cost

.08

.10

Non-FTS Share of Labor Cost

Source: As calculated in the text. 
To estimate expenditures on non-FTS labor we multiplied non-FTS hours by the area wage facing the establishinent and reduced the amount by the ratio of the average hourly earnings of retall trade nonsupervisory workers to the average hourly earnings of manufacturing workers in 1977, as reported in Employment and Earnings, March 1978 (the retail trade average was $\$ 3.83$; the manufacturing average was $\$ 5.63$, giving a ratio of .68).

We report results for the entire period covered by our data and for the latest full year for which we have data, 1978. We report results for the entire sample and for users only.

We find that full-time student labor has a cost share of $4 \%$ to $10 \%$ depending on the group and time covered.

Table 12 combines these figures with three alternate values of $\sigma$ from Table 10 to test the impact of different elasticities on changes in FTS and non-FTS hours: (1) a low estimate of .5 using column 3 , (2) a medium estimate of 1.2 using column 4, and (3) a high estimate of 2.4 using column 6 . In each case the values are obtained by solving equation (5) for $\sigma$, by dividing the coefficient on the cost of alternative labor by the coefficient on the non-FTS hours variable. Lines 1 and 4 record the elasticities of fixed output labor demand implied by the estimates for FTS and non-FTS workers respectively, using equations (10) and (11). Since the FTS share in costs is relatively modest, the elasticity in line 1 far exceeds that in line 4 . Lines 2 and 5 multiply the relevant elasticities by the .15 reduction in wages to obtain estimates of the change in In man hours worked by the two groups. According to these calculations, the effect of the subminimum on employment of FTStype labor strongly depends on the estimated $\sigma$. For the smallest value for $\sigma$ in Table $12(.5)$, the effect of the $15 \%$ reduction in the minimum wage on employment of FTS labor is $7 \%$. Using the largest value for $\sigma(2.4)$ 
TABLE 12 : ESTIMATED IMPACT OF THE STUDENT SUBMINIMUM ON FTS AND NON-FTS HOURS WORKED

Assumed Value of $\sigma$

$\begin{aligned} \begin{array}{c}\text { Using Mfg. } \\ \text { Wage Without } \\ \text { Region Controls }\end{array} & \begin{array}{c}\text { Using Mfg. } \\ \text { Wage With } \\ .5\end{array} \\ 1.2 & \begin{array}{c}\text { Using } \\ \text { Annual Earnings Controls } \\ \text { Region Controls }\end{array}\end{aligned}$

FTS Labor

1. Fixed Output demand elasticity, with FTS share of costs at $5 \%$

2. Change in In FTS hours with $\dot{W}=.15$

3. Absolute change in FTS hours for mean establishment sample

Non-FTS Hours

4. Fixed output demand elasticity with FTS share of costs at 58

5. Change in In non-FTS hours with $\dot{W}=.15$

.004

.009

.018

6. Absolute change in non-FTS hours for mean establishment sample 
this employment effect is $34 \%$. Regardless of the assumed $\sigma$, the decrease in non-FTS employment is less than two percent.

Since FTS hours are a modest share of total hours, however, these sometimes large differential percentage changes in employment for the two groups translate into more modest differences in actual hours of employment. According to the figures in line 3, hours worked per establishment by FTS-type labor increased from 248 to 1194 using the smallest and largest estimates of o respectively. For non-FTS hours, the decrease ranges from 156 to 745 hours per establishment for the low and high values of $\sigma$, respectively. Using our middle estimate of $\sigma(1.2)$ we find an increase of FTS hours of 597, partly offset by a decline in non-FTS hours of 374 .

\section{Full Demand Effect}

To estimate the total impact of the youth subminimum on hours worked, it is necessary to add in the scale effect and any substitution between capital and the like. We focus here on estimates of the scale effect. We obtained from Mary Corcoran of the Institute of Social Research an estimated elasticity of the demand for retail trade activities. This elasticity was calculated by a survey of establishments that asked them their perception of the elasticity. It suggests a moderate scale effect of 1.0. If we take the FTS share of labor as $5 \%$ of labor cost, and use national income statistics to estimate labor's share of national income in retail trade, we obtain an estimate of the impact of the reduction in the wage of students on cost. According to the national income statistics (Survey of Current Business, July 1979) compensation of labor in retail trade was $\$ 113$ billion; national income in the sector was $\$ 185$ billion, giving a share of .61 . Hence, our estimate of the scale effect is $.05(.15)(.61)=.0046$. By the estimated elasticity of demand, the resultant scale effect is $.46 \%$. A $.46 \%$ increase in the average hours of employment in an establishment (approximately 45,000 in our sample) would translate into an employment scale effect of 200 hours. If this number 
is reasonable, the scale effect is potentially an important employment effect equivalent in magnitude to the estimates for the decrease in non-FTS hours presented in Table 12 .

\section{Substitution of Whom for whom}

It would, for policy purposes, be interesting to know whether the non-FTS people displaced are nonstudent teenagers or "adults". If it turns out to be the former, one would be inclined to guess that a general teen differential would have less effect than if there was substantial FTS teen/adult substitution.

To get a handle on the substitution question, we re-interviewed six major corporations who had participated in our initial survey. We asked, "If the subminimum wage provision were not part of the Fair Labor Standards Act, would the work that is now being done by the full-time students :

(1) not be done at all?

(2) be done by other staff members without hiring any new people?

(3) or would have hired someone to do this work, and if so, from what age group?"

The predominant answer was that students would have been hired regardless of the provision, though one establishment said they would have divided up the work among existing employees. Hence, for what it is worth, we feel that much of the substitution may be between student labor and other youth labor.

For policy purposes it would also be of value to learn about the views of managers toward the FTS program. Accordingly, we obtained the permission of some companies to contact individual establishments. We asked each establishment for infommation on hours per week worked by both regular employees and full-time students similar to the information asked of the companies. We also asked for a count of full-time, part-time, and full-time-student employees, for a qualitative measure of the establish- 
ment's likely response to different changes in the law and the reasons for under-utilization of the certificate by the establishment. Because this data comes from the establishment manager who is usually responsible for the hiring decisions, it provides a valuable perspective on the operation of the FTS program.

Table 13 presents some of the results from the establishment questionnaire regarding reasons for under or nonutilization of the program and responses to changes in the program.

All establishments which did not use the maximum allowed hours at the subminimum (and only 14\% reported using the maximum) were asked how important each of ten possible reasonsifør underutilization were. These responses are presented in panel A. The difficulty of substituting FTSs for other workers is apparent in the two reasons cited most often as "very" or "somewhat" important: "we need some nonstudents to work when FTSs cannot (due to school commitments)" mentioned by $78 \%$ and "we need adult workers for stability and continuity of our work force" mentioned by $72 \%$. We also see that this difference between FTSs and other workers is one of substitution, not a strict difference in the productivity of the two groups, as only $26 \%$ cited "full-time students are unsatisfactory workers; we prefer adult workers" as a reason for underutilization.

That employment of FTS labor is influenced in part by supply is indicated by the fact that $46 \%$ of respondents said that "we cannot find full-time students willing to work at a subminimum wage" was an important reason for underutilization. "Our company policy is to pay all workers at least the minimum wage" was also mentioned by $54 \%$. State restrictions on program use were cited by fewer than one-third of the respondents. Unionism was not accorded an important role, suggesting that the union impact operates largely on whether or not a company uses the program at all. 
TABLE 13: EMPLOYER VIEWS OF USAGE OF FTS PROGRAM

REASONS FOR UNDER OR NON-UTILIZATION OF PROGRAM

Reason

Frequency of Responses (\% of responses)

\begin{tabular}{lll}
\hline very & somewhat & not important/ most important \\
important & important & not applicable of those given
\end{tabular}

a. Our company policy is to pay all workers at loast the minimum wage.

$\begin{array}{rrrrrr}75(28) & 70(26) & 122(46) & 4 \\ 58(21) & 89(33) & 125(46) & 27 \\ 73(27) & 123(45) & 76(28) & 22 \\ 68(25) & 54(20) & 150(55) & 7 \\ 108(40) & 103(38) & 60(22) & 7 \\ 25(10) & 56(21) & 177(69) & 8 \\ 13(5) & 56(21) & 203(74) & 3 \\ 52(19) & 78(29) & 141(52) & 2 \\ 56 & (21) & 60(23) & 147(56) & 4 \\ 15 & (0) & 7 & (3) & 233(91) & 0\end{array}$

RESPONSE TO CHANGE IN PROGTAM

a. Paduce the wage paid to FISs by 50 cents per hour ( 50 cents below what is currently allowed under the FIS Program).

$44(16) \quad 97(34) \quad 143(50)$

$51(24)$

b. Renove the limit on hours a FIS can work in a given week.

$87(30) \quad 118(41)$

$82(29)$

$70(29)$

c. Renove the restriction on percentage of total hours allowed to be paid at the sulminimm wege.

78 (27) $129(45)$

$79(23)$

32 (13)

d. Permit any teenager, not just FISs, to be pald the Eubminimm wage.

72 (25) 105 (37) 106 (38)

$43(20)$

e. Remove the requirement that adult workers not be displaced by FISs.

31 (11) $86(31) \quad 164(58)$

f. Renove ill state restrictions on your ure of the ris Progran.

$57(20) \quad 110(39) \quad 115(41)$

$23(10)$

Source: Our questionnaire. 
The managers were also asked what was the most important reason for their underutilization of the program. Relatively few responded to this question, and those that did cited a wide variety of reasons, not all appearing on this list. However, of the questions on this list, difficulty of finding students willing to work at the subminimum was mentioned 27 times and the need for adult workers for stability and continuity was mentioned 22 times. No other reason on the 1 ist was mentioned more than eight times. This points out the impact of a limited supply of workers at the subminimum wage: it does not affect as many establishments as the problem of substituting FTSs for other workers, but for those affected it is important.

In addition to these questions on current program use, the managers were asked whether each of six hypothetical changes in the program regulations would lead to a "substantial", "limited", or "no" increase in their use of the program. These responses are also presented in Panel $B$. The two most often mentioned are "remove the limits on hours an FTS can work in a given week", mentioned by $71 \%$ and "remove the restriction on percentage of total hours allowed to be paid at the subminimum wage" mentioned by 72\%. The latter restriction could be related to the month-by-month limits on the percentage of subminimum hours allowed: even if the establishment is not always at the maximum, it might be at certain times of the year. By reducing these restrictions, managers perceive that their ability to substitute FTSs for other workers would increase. Broadening the class of eligible workers was somewhat less important: $62 \%$ cited "permit any teenager, not just FTSs, to be paid the subminimum wage". Removing the state restrictions was mentioned by $59 \%$, and removing the prohibition on displacing adult workers by only $42 \%$. Compatible with our finding that the demand for FTS labor is affected by relative wages, 50 percent said that reducing the FTS wage by 50 cents would increase their use of the program. 
The managers were asked which of these changes would have the greatest impact, providing another measure of the importance of the changes. Removal of the limit of 20 hours per week worked at the subminimum is cited as most important by $29 \%$, while the overall establishment ceiling was mentioned by only $13 \%$. The reduction in FTS wages also affects some establishments' strongly, with $24 \%$ saying it was the most important change 1 isted. Allowing any teenager to be paid at the subminimum wage was most important to $20 \%$, while state restrictions and non-displacement of adult workers were rarely considered nost important.

We also asked the establishment managers a series of questions on the incentives provided to them by the company to use the program. Their responses were matched against those given by the company. We found some disagreement between the company and establishment responses: in cases where the establishment reported no rewards for good performance, 30 percent of the companies reported some rewards. This disagreement between company and establishment perceptions is less pronounced for pressures specifically directed at increasing program usage. In 19 percent of the cases for which the establishment reported no pressure to use the program, some pressure was reported by the company. This sort of misperception would lead our estimates of the impact of company policies to be an underestimate of the impact of fully recognized policy. The better performance of the more direct pressures may in part be due to better communication of the specific policies by companies to their establishments.

There is also disagreement between establishments and companies on the difficulty of finding reliable workers at the minimum wage. Only $5 \%$ of managers, but $55 \%$ of companies, said it was "easy" (though $36 \%$ of mangers said it was "not too difficult"). Only $3 \%$ of the companies, but $18 \%$ of the managers said it was "very difficult". These differences are in part due to the $40 \%$ of the companies that answered "it varies (between establish- 
ments)", but companies in general seem to have an exaggerated idea of the ease of finding reliable workers at the minimum wage. This provides some support for our hypothesis that, at least in some areas, non-FTS workers are relatively difficult to find at the minimum wage, which would increase the attractiveness of hiring FTS workers at the subminimum.

Finally, we asked the managers "did participation in the FTS Program influence your establishment to expand total employment by more than might otherwise have occured?" If it had, they were asked to indicate the number of additional workers hired. Thirty percent answered that employment had increased. For these establishments, on average, five or six additional workers were hired as a result of the program, according to establishment managers. This compares to an average total employment of just over 24 employees per establishment in the sample. This again indicates that the reduction in the wage for this group of workers has had an effect on FTS employment.

These results from the establishment questionnaires support our previous conclusions that students (or at least full-time students under the current program) are imperfect substitutes for regular workers. This is partly due to their student status, which carries higher turnover rates and less flexible work schedules. It is also due to program restrictions on both individual and aggregated subminimum hours. There may be paperwork costs associated with the program, but since all these establishments are already involved in the program we have no means to test for the importance of these costs. Naturally, we would assume that the existence of such costs would make students even more difficult to substitute for regular workers, so that larger changes in relative wages would be needed to induce the firms to expand student employment. 
Biases and Problems With the Analysis

Our analysis is subject to several problems which should be brought forth. First, our sample dealt solely with firms who were in the $10+\%$ category, who are FTS intensive. We suspect (although it does not follow inevitably) that these firms also find it easier to substitute FTSs for other workers -- one reason that other firms are not in this category would be that they find such substitution more difficult than the firns in our sample. Second, to the extent that some establishments are at their certification ceiling, then the number of FTSs they are hiring is less than the cost-minimizing number, and the estimated "elasticity of substitution" is not as large as the "true" elasticity. With our data, we are unable to gauge the relative importance of these biases.

Implications for a General Youth Subminimum

Our findings suggest a responsiveness of employment to the FTS program to relative wages. What then can be said about a general youth subminimum?

Several features of the FTS program suggest that generalizations are difficult. On the one hand, the FTS program is limited to certain sectors of the economy where a priori, one might expect greater ease of substitution between youth and other workers -- the retail/service sector is one with relatively many unskilled workers. We also selected significantly large users of FTS labor, for which our estimates of substitution might be expected to be especially high. On the other hand, as noted, one of the major deterrents to substitution is the difficulty of accomodating the peculiar time schedules of students and the time constraints of the program. Nonstudent youth might be easier to substitute for older 
workers. Indeed, many managers mentioned that allowing them to hire any teenager, not just a student, at the subminimum would induce a substantial change in program use. This suggests that there would be a greater response by employers to a youth subminimum than our data suggest. However, nonstudent youth may not be as willing to work at the subminimum as students.

Finally, the ability to draw generalizations about a general youth subminimum directly from the results presented here is limited by the sensitivity of the effect of area wages on FTS employment to the various specifications, particularly in the absence of any satisfactory explanation for the effect of region controls on certain wage coefficients. 
Appendix A: Development of the Data Set

Our study was obligated to create its own data base in order to analyze the student subminimum. The design by which we collected data was motivated by and ultimately determined our research analysis. As noted in Section III, we obtained data from three basic sources:

- administrative records on employers certified to hire FTSs

- our own telephone survey of over 200 such employers

- published data on area labor market conditions.

This appendix provides a detailed description of the process by which we collected data and the resultant data set.

\section{Administrative Record Data}

Our primary source of information on use of the program was the Department of Labor's file of employer applications for certification under the program. Every year each establishment in the program must submit a renewal application, including the number of hours paid to all employees in the previous year, and the number of hours paid at the subminimum wage. One copy of the application is kept by the Regional office (which handles the day-to-day administration of the program) and one copy is forwarded to the National office in Washington, D.C. to be placed in the national file. (See Table A-1 for a copy of this form).

This data is aggregated into a quarterly report on program usage by each Regional Office, from which the National office prepares quarterly and annual totals for the nation as a whole. These reports represented the only previously existing information on program use, and are in too aggregate a form for detailed analysis. Nonetheless, we used this data 
for preliminary investigation of how usage has changed over time, and also to give us some idea of the scope of program usage.

From the first it was clear that we would have to use the application files to develop a sample of program users. An early decision was whether to use the files at the Regional or National level. The Regional files maintain separate folders for each establishment, regardless of the certificate class ( 6 or fewer, 10 percent, or over 10 percent) containing all past applications for that establishment. However, using Regional files would require visits to several cities to develop a comprehensive national data base. The National files contain all past applications for the entire country, but separate folders are only maintained for establisiments in the over $10 \%$ class. These folders are arranged in order by parent company, which aids in analyzing differences between companies. Because of the difficulty involved in visits to different Regional offices, we decided to use the National files and restrict our sample to users in the over $10 \%$ class. We considered only retail and service establishments, since agricultural establishments represent little of overall usage and institutions of higher education have special motivations for hiring their own students.

Even this restriction of the sample was not quite enough to provide a data set of manageable size, so we further restricted the sample to those establishments in companies that had ten or more establishments enrolled in the program. One reason for choosing this restriction was to simplify collection of data from the parent companies. A further reason was that an earlier study done in 1969 by the Department of Labor suggested that nearly all of the aggregate hours worked under the program were accounted for by 
the largest 10 or 20 multi-establishment companies (most of which are now in the over $10 \%$ class). We finally obtained a sample of 7,874 establishments in the over $10 \%$ class, belonging to fewer than 200 parent companies. From the files in Washington, D.C., we collected a history of each establishment's use of the program: total and FTS hours from each year's renewal form (up to 12). We also obtained a few minor pieces of information, including sales volume (one of three categories), zip code for identifying geographic location so that we could later add data on local labor market conditions, the addresses of the establishment and parent company, and the name and telephone number of the person responsible for the application (typically the personnel manager of the parent company). It was this information which enabled us to proceed with further data collection. of our sample of 7874 establishments that were in the program in 1974, 2915 were no longer in the program by 1979. The establishments are included in our analysis for every year in which we have data, but no correction is made for their dropping out. 


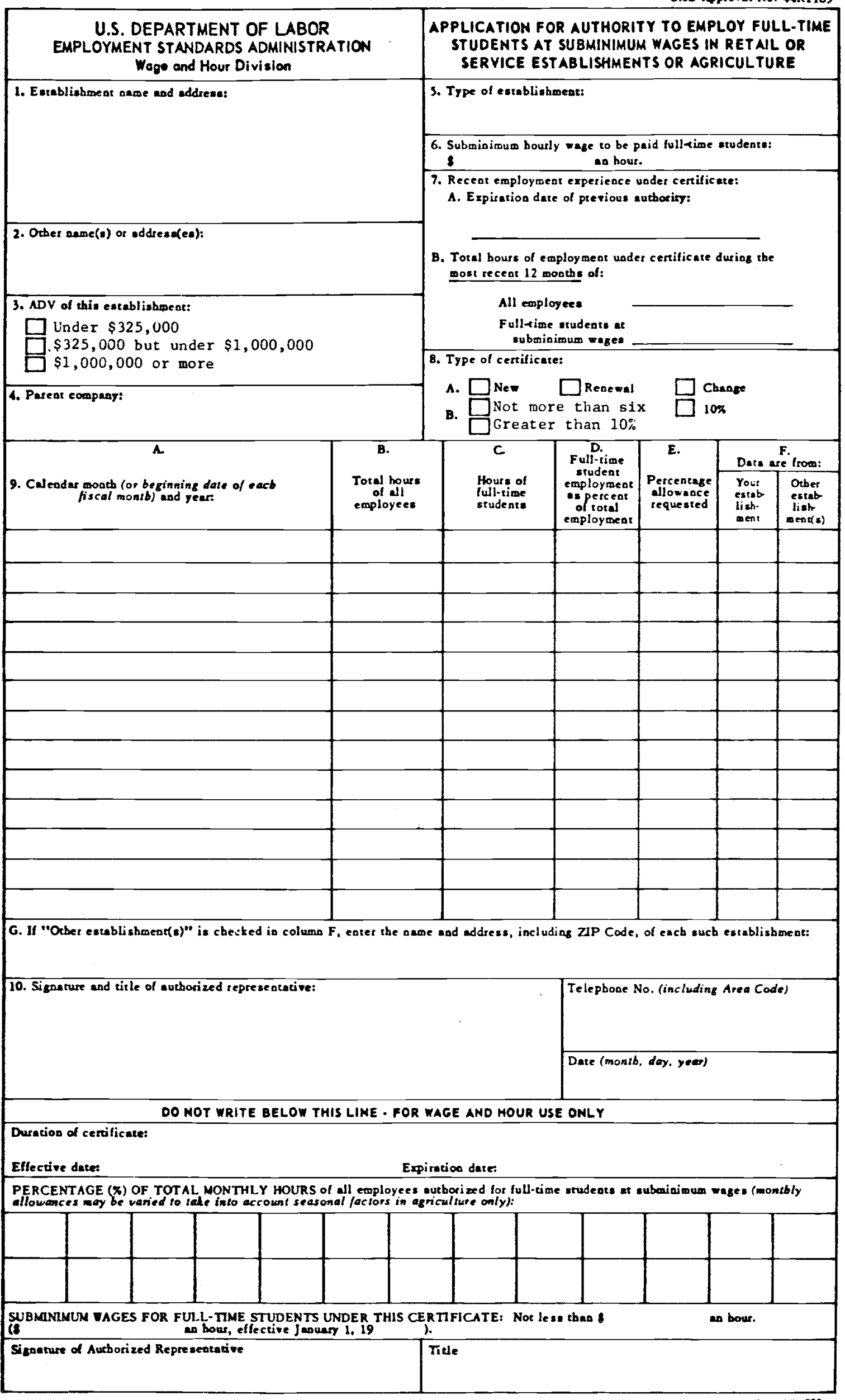




\section{Our Telephone Survey}

From the information on application forms we obtained, as noted earlier, the name and address of persons responsible for the program. To obtain additional information about companies using the program we decided to conduct a telephone survey of the responsible officials.

Before contacting any of the companies or establishments from our sample, we used the application file in the Boston Regional office to identify several users of the program in the local area. This set of companies and establishments was used to test several preliminary versions of the questionnaire before national use. We also received many helpful suggestions from the users on alternative questions to ask. Finally, this procedure gave us some early indication of what answers to expect from the larger sample.

During the second stage of data collection on the national level, each ccmpany was contacted about the study by telephone. They were asked a series of questions designed to provide us with information about the company's use of the program, focusing especially on the average hours per week and weeks per year worked by regular and full-time student workers and the reasons for differences in use across establishments. The earlier questions were intended to let us estimate the number of students actually employed under the program. We attempted to collect a history of program usage from the companies, including number of students hired as well as number of hours worked, but this proved too time consuming for the companies to complete. Of the initial 7,874 establishments, 5,557 were in companies from which we collected data. The remaining companies were either uncooperative or impossible to trace.

Tablè A-2 shows the telephone survey instrument used in our analysis. 
HETIO, MY NAME IS WITH THE NATJONAI BUREAU OF EOCNOMIC FESEAFCH IN CAMBRIDGE, MASSAOULSETTS. WE AFE CONDUCTTNG A STUDY OF THE USE OF A PRONISION OF THE FAIR IABOR STANDAROS ACT TMAT ALLOWS DMPLOYERS TO HIRE FULI-TIME SIULENTS AT A SUBMENIMUM WAGE. WE AFE CONTACTING (firm name) BECAUSE YOU AFE LISTED AS HAVTNG BEDN ALTHORI ZED TO JODN THIS PROGRAM. WOUD YOU BE WILING TO SPDND A FEN MINUTES PASTERNG SOME QUESTIONS ABOUT YOUR COMPANY'S USE OF THIS PFOGRAM? NAME OF CONTACT AND TITLE: TEIEPHONE NLPER: area code phone number

1. WHEN DID YOUR COMPANY FIRST HEAR ABOUT THE FTS PFOGRAM?

2. WHEN DID THE COMPANY FIPST APPLY? manth year

3. HON DID THE COMPANY FIRST IEAPN ABOUT THE PROGRAM?

4. HOW MANY ESTABLISHMENTS ARE YOU FESPONSIBLE FOR?

5. EXCUUDTNG RECENILY OPENED ESTABLISHFENIS, ARE ALL THESE ESTABLISHMETS CURKENTLY ENROLLED TN THE PRCGRAM? IF NO, WHAT PERCENTACE ARE? WHY ARE SOME ESTABLISHMENIS NOT ENPOLLED IN THE PROGRAM?

6. DOES TME DEGKEE TO WNICA ESTARLISHAESTS UTHLZB THE PROGRAM VAPQ SUBSTANTIALLY AMONG ESTABLISHRENTS?

IF YES, WHY?

7. IS ANY PRESSURE OR TRCONTIVE GIVDN TO THE ESTABLISHMENT MANAGEPS TO ENDCURAGE THEIR USE OF THE PFOCRAM? IF YES, WHAT KDND?

8. IS THE MANAGER FENARDED FOR HOLDING DOWN PAYPOLL COSTS BY HIRDNG FTSS (WITHOTT REDUCDNG THE LEVEL OF SERVICE PFOVIDED)?

IF YES, HOW?

9. IN GENERAL, HOW DIFTICITT IS IT FOR THE ESTABLISHMNI MAUACERS TO FDD FEIJABLE, UNSKULIED WOFKEES AT TME MTNIMM WAGE?

10. DO ANY OF YOUR ESTABLISHMENTS HAVE DMPIOYEES WHO AFE UNION MEMBERS? IF YES, WHAT PERCENTAGE OF AN ESTABLISHMENT WOFK FORCE DO THEY CONSTITUTE? ARE NEWLY HIFED FTSS FEQUIFED TO JONN A UNION? IF YES, DOES THIS LIMIT YOUR USE OF THE FTS PFOGRAM?

11. THE LAST FEW QUESTIONS PERTATN TO HOUTS AND WEEXS WOFEED BY ADULT AND STULENT DMPLOYEES. YOU MAY NOT KNOW EXACT MURERS, BUT WE WOUD APPRECIATE YOUR BEST ESTDMATE. WHAT WOID YOU SAY WERE THE:

a. AVERAGE HOUFS PER WEEK WORED BY A TYPICAL, NONFTS EMPLOYEE?

b. AVERAGE WEEKS PER YEAR WORKED BY A TYPICAL, NONFTS EMPIOYEE?

c. AVERAGE TIME A TYPICAL, NONFTS PMPIDYEE STAYS WITH YOUR COMPANY?

d. AVERAGE HOURS PER WEEX WORKED BY FTSS DURING THE SOHOOL YEAR?

e. AVERAGE HOURS PER WEEK WORKED BY FTSS DURDNG VACATIONS?

f. AVERAGE IENGTH OF TIME A FTS STAYS WITH YOUR COMPANY?

g. HOURLY WAGE PAID FTSS?

h. HOURLY WAGE PAID NONFTSS IN THE SAME JOB FOR WHICH FISS AFE HIRED?

SINCE MANY OF THE CRUCIAL ISSUISS DEALING WITH UTILIZATION OF THE PFOGRAM AFE DECIDED AT THE INDINIDUAL ESTABLISHIENT IEVEI, WE WOUD LIKE TO SEND A SHORO, ONE-PACE QUFSTIONNAIFE TO EACH ESTABIISHMENT THAT USES THE PFOGRAM. ALI DNFORMATION PRONIDED WILL BE USED TO PFEPAPE STATISTICAL TOTALS AND WILL NOT IN ANY WAY BE IDENTIFIED WITH YOU OR YOUR OOMPANY. BEFORE WE DO THIS, WE WOULD LIKE TO SEND YOU A COPY OF THE QUESTIONNAIRE TO GET YOUR COMENIS AND APPFONAL. WOULD THIS BE ALRIGT? IN OUR EXPERIENCE, MANAGERS ARE REIUCTANT TO RESPOND TO QUESTIONNAIEES WITHOUT SOME SORT OF CLEARANCE FROM THEIR CENTRAL OFFICE. IF YOU APPROVE OF THE QUESTIONNAI RE, WOULD YOU BE WILLNG TO SEND A MEND TO THAT EFFECT TO THE MANAGERS? OR COID WE ENCLOSE A NOTE FROM YOU WITH OUR QUESTIONNNAIFE TO THE MANAGERS? WOID YOU LIKE A COPY OF OUR FESULTS FOR YOUR COMPANY WHEN WE HAVE COMPLEIED THE STUDY? 
Data on Labor Market Conditions

Some data on local labor market conditions were added to the data set. The SMSA and state were identified using the zip code of the establishment. Then the area unemployment and manufacturing wage rates for 1971 to 1978 were added to each establishment's record. If the establishment was not in an SMSA, the value for the balance of the state outside of SMSAs was used. This data was available for nearly all of the establishments in the data set. The area unemployment rates were obtained from the Employment and Training Report of the President, 1973-78. The manufacturing area wage rates were obtained from Employment and Earnings, May 1972-79.

Note that because only manufacturing wages are available on a detailed local labor market basis, we have used these wases rather than the potentially more appropriate retail traie wages. To check. on the possible problem due to use of manufacturing wages on our measure of local market conditions, we used data from the 1970 Census of Population state books, to see how the two measures vary together on a geographic basis. We took a weighted average of the annual median earnings of men and women year-round, full-time workers in the two sectors, using as weights the fraction who were male or female, and regressed the log of the manufacturing wage, so calculated, on the $\log$ of the retail trade wage. The results show the two wages move together to a significant extent: the simple correlation between the two series across the states is .87 . The regression coefficient of In manufacturing wages on in retail trade wages is 1.11 with a standard error of .10. This suggests that the area wage we used overstates the wages paid by retail trade establishments policy by a roughly constant proportion. Because of the close link between the two series, results based on the 
more appropriate but unavailable retail trade series are likely to yield results much like those we obtained. If we regard the manufacturing wage as a proxy with error for the retail trade wage, our regressions are likely to understate the true responsiveness to wages by the usual measurement error arguments. However, it is likely that the difference between the manufacturing and retail trade wages reflect labor market conditions that are correlated with our other variables. Hence we do not apply the measurement error argument to our estimates. If we did, we would strengthen our findings of sizeable response to wages.

Additional labor market conditions for 113 SMSAs were collected from 1970 Census of Population publications. As an alternative measure for area wages, the mean annual earnings of prime age (30 to 34 year old) workers was added to the data set. Also added were the mean annual earnings for 16 to 19 year olds who report earnings, the size of the 16 to 19 year old student population, and overall SMSA population. These variables were added using the establishment zip code; however, since balance-of-state values for observations not in SMSAs were not available from these sources, these data are used in the analyses for the sample of establishments in SMSAs, and for the full sample of establishments using dummy variables to indicate the establishments not in SMSAs for which there are missing values.

\section{Establishment Data}

Finally, we contacted the individual establishments. We asked each establishment for information on hours per week worked by both regular employees and full-time students similar to the information asked of the companies. We also asked for a count of full-time, part-time, and full-time-student entployees, for a qualitative measure of the establishment's likely response to 
different changes in the law and the reasons for under-utilization of the certificate by the establishment. The questionnaire is available on request.

In order to obtain the best possible response rate from establishments, we sent copies of the establishment questionnaire to the parent companies for their approval. After they approved it, they sent us a written approval for distribution with the questionnaire, or sent a memoranda to their establishments directing them to complete the questionnaire and return the completed forms to us. We obtained information on 316 establish$\because$ ments. Of these, 225 have been matched with the administrative data (some of the remainder are new establishments or ones not enrolled in the program). Because of the small sample of establishments, most of our analysis has been done using administrative and company data, with the establishment data used primarily for checking consistency with the company data.

The final result of the data collection is a data set containing over 20,000 establishment years from 1971 to 1979 with information on program usage (both hours worked and estimated number of students hired), local labor market conditions, and some data on the parent company. 


\section{Footnotes}

1/ For an earlier examination of the use of the full-time student certificate program, see Clara F. Schloss, "Study of Full-Time Student and Learner Certification Programs Under the Fair Labor Standards Act," in Youth Unemployment and Minimum Wages, U.S. Department of Labor Bulletin 1657,1970 .

2/ U.S. Department of Labor, Employment Standards Administration Wage and Hour Division, "Regulations, Part 519: Employment of Full-time Students at Subminimum Wages, 29, C.F.R., $\$ 519$ (1975), (Washington, DC: U.S. Government Printing Office, 1976): "Fair Labor Standards Act of 1938 (As Amended by the Fair Labor Standards Amendment of 1977) And Related Provisions of Law," Sections 6, 13, and 14 (Washington, DC: U.S. Government Printing Office, 1978).

3/ The minimum wage has changed frequently in the last 20 years:

to $\$ 1.15$ (on $9 / 61$ ), $\$ 1.25$ (on $9 / 63$ ), $\$ 1.40$ (on $2 / 67$ ), $\$ 1.60$ (on $2 / 68$ ), $\$ 2.00$ (on $5 / 74), \$ 2.10$ (on $1 / 75), \$ 2.30$ (on $1 / 76), \$ 2.65$ (on $1 / 78$ ), $\$ 2.90$ (on $1 / 79$ ), $\$ 3.10$ (on $1 / 80$ ), and $\$ 3.35$ (on $1 / 81$ ). The FTS subminimum has always been exactly $85 \%$ of the minimum wage. Thus it went from $\$ .98$ per hour in 1961 to $\$ 2.85$ in 1981 .

4/ National League of Cities v. Usery, 426 U.S. 833, (1976).

5/ A small number (7) of companies in our survey did report paying above the $85 \%$ of the minimum but below the minimum, see p. 18 .

6/ Indeed, our establishment survey results in Table 13 show that $21 \%$ of respondents said that an important reason for under-utilizing the program was that they could not find students willing to work at the subminimum. Another $33 \%$ said this was somewhat important. That leaves, however, roughly half (46\%) of employers who did not feel so constrained. 
7/ The assumption that supply elasticities are the same for $\mathrm{C}$ and $\mathrm{w}_{\mathrm{S}}$ is made purely for convenience.

8/ We obtained similar results in calculations in which we excluded observations in which data was missing. For the analysis which includes observations with missing local labor market information, we used dummy variables to indicate whether the information was missing and replaced the missing value with the mean value from those observations for which the value was present.

9/ The reason why more student labor is not used under all circumstances could be that the students' unavailability during school hours and during other school activities makes scheduling workers more difficult, while the students' higher turnover might make them less desirable or at least require some nonstudents to provide stability to the work place. While a few students might be hired under any circumstances, there might be a substantial wage differential before the establishment is willing to greatly increase its use of students. This result does not imply that students are poorer workers in general (such an assumption was not supported by our company interviews), but have a less than infinite elasticity of substitution with other workers.

10/ A regression was done on the SMSA subsample of log prime age earnings on $\log$ area wage as well as the other independent variables used in the Table 7 regression. The coefficients from that regression were used to generate a predicted log prime age earnings value for the entire sample, which was then used in columns 5 and 6 of Table 7 as a substitute for the log a rea wage. 